\title{
A abordagem ontológica da identidade social de Davis e as posições de outros autores na Economia recente
}

The ontological approach of Davis' social identity and the positions of other authors in the recent Economics

\begin{abstract}
Unlike Akerlof and Kranton for whom social identities are formed by eigenimages built by social categories, of March who considers as synonyms identities and social roles, of Sen and of Kirman and Teschl who reference the existence of only social and personal identities, Davis defines three categories of identities: social, individual and personal. Davis defines social identity with the ontological construction of a socialized individual and consists of cognitive and institutional aspects. The aim of this paper is to present the ontological approach of the individual in the Economics through the concept of social identity John B. Davis and its differentiation with the approaches of other authors who also work the question of identity in the Economics, such as Akerlof and Kranton, March, Sen, Kirman and Teschl. It is considered that Davis's contributions ontologically grounded in the individual are superior to those of other authors of the recent Economics.
\end{abstract}

\section{Keywords}

social identity; individuals; recent Economics.

JEL Codes B50; B59.

\author{
Aline Zulian (1) \\ Solange Regina Marin (2) \\ Orlando Martinelli Júnior ${ }^{(3)}$ \\ (1) Universidade Federal do Rio Grande do Sul \\ (2) Universidade Federal de Santa Catarina \\ (3) Universidade Federal de Santa Maria
}

\section{Resumo}

Diferente de Akerlof e Kranton, para quem as identidades sociais são formadas por autoimagens construidas por categorias sociais, de March, que considera como sinônimos as identidades e os papéis sociais, de Sen e de Kirman e Teschl que referenciam a existência de apenas identidades sociais e pessoais, Davis define três categorias de identidades: sociais, individuais e pessoais. Davis define a identidade social com a construção ontológica de um indivíduo socializado e constituído por aspectos cognitivos e institucionais. O objetivo deste artigo é apresentar a abordagem ontológica do indivíduo na Economia por meio do conceito de identidade social de John B. Davis e da sua diferenciação com as abordagens de outros autores que também trabalham a questão das identidades na Economia, como Akerlof e Kranton, March, Sen, Kirman e Teschl. Considera-se que as contribuições de Davis, ontologicamente fundamentadas no indivíduo, são superiores às de outros autores da Economia recente.

\section{Palavras-chave}

identidade social; individuos; Economia recente.

Códigos JEL B50; B59. 


\section{Introdução}

Um dos temas mais importantes da Ciência Econômica é a compreensão do comportamento e das decisões do indivíduo. Longe de ser consensual, ao longo do tempo verifica-se uma história de oposição entre as correntes da Economia Pura/Tradicional - individualismo metodológico - e a da Economia Política - holismo metodológico. A disputa entre essas duas vertentes está entre: i) indivíduo e comportamento explicados pela construção intrinsecamente individualista e privada no que diz respeito às suas relações de mercado; ii) indivíduo concebido por meio de suas relações externas, isto é, o mundo social é parte constitutiva da construção da categoria indivíduo. Ou seja, enquanto que o individualismo metodológico entende que as teorias econômicas são redutíveis à ação humana individual, o holismo está preocupado com as influências sociais que incidem sobre a ação individual, de modo a negar que os fenômenos sociais podem ser explicados pelo comportamento individual (Rutherford, 1994).

Com essa disputa permanente entre o individualismo e o holismo metodológico, abordagens mais recentes, que abrangem a neuroeconomia, a economia comportamental e a economia da complexidade, ampliaram a visão de individualismo no sentido de considerar não apenas os indivíduos, mas os indivíduos e também as estruturas/relações sociais. Hodgson (2007) descreve que existem ambiguidades na definição de individualismo metodológico em conceber os indivíduos isoladamente ou permitir explicações em termos de indivíduos mais relações. Ou seja, análises baseadas em indivíduos sozinhos, isolados, não possuem sustentação, e uma "versão mais viável" seria considerar os indivíduos mais as relações entre eles (Hodgson, 2007).

Apesar de o termo "individualismo metodológico", criado pelo economista Joseph Schumpeter (1908 apud Hodgson, 2013), referir-se em sua concepção a uma conduta metodológica de iniciar a descrição de certas relações econômicas a partir do indivíduo, posteriormente ao falecimento de Schumpeter, o termo ganhou maior difusão, mas com outros significados (Hodgson, 2013). Entre os vários significados que foram atribuídos, um dos mais difundidos, e problemáticos, foi conceituar o individualismo metodológico em termos de indivíduos isolados. O problema dessa definição, segundo Hodgson (2007), está em não transparecer se as explicações devem ocorrer com base em indivíduos mais suas relações, ou em termos 
de indivíduos sozinhos. Na verdade, conforme o autor, essa segunda concepção não é alcançável, de modo que a explicação poder ocorrer com o surgimento de instituições mais indivíduos.

Hodgson (2007) destaca que explicar o surgimento de instituições com base em indivíduos "dados" também possui limitações ("quem vem antes?"). Então, com base no autor, uma versão mais ampla do individualismo metodológico seria considerar explicações em termos dos indivíduos e das relações entre eles, isto é, considerar os fatores sociais com base nos indivíduos e nas estruturas sociais. A questão que o autor apresenta é por que chamar de individualismo metodológico um termo que considera, em um mesmo plano, indivíduos e estruturas? Assim, Hodgson (2007) sugere abandonar o termo, a não ser que ele venha acompanhado de uma explicação clara que supere as ambiguidades do passado. ${ }^{1}$

Chafim e Krivochein (2011) também destacam problemas na forma de conceituar o "individualismo metodológico" e apresentam os significados do princípio individualista no plano ontológico, epistemológico e metodológico. Segundo os autores, não é possível explicar uma teoria social partindo apenas de indivíduos sozinhos, uma vez que eles interagem entre si e com as estruturas. Em outras palavras:

Explicar fenômenos ou arranjos sociais apenas como resultado da deliberação humana reduz problemas sociais a questões psicológicas. Por outro lado, argumentos em termos de estruturas socioeconômicas, indivíduos e suas diversas interações, aumentam a capacidade explanatória da teoria social. (Chafim; Krivochein, 2011, p. 55).

A disputa histórica entre individualistas e holistas restringe-se ao método que é utilizado para a estruturação da teoria econômica; não discute-se quem é esse indivíduo, como ocorre no âmbito da ontologia. A argumentação defendida neste artigo é de que o debate em torno do indivíduo, e do individualismo do mainstream, centrou-se nos aspectos metodológicos e não nos fatores ontológicos. Este artigo identifica-se com a perspectiva que

1 Nesta mesma linha, Kerstenetzky (2007) destaca outras formas de definir o individualismo metodológico e de superar essa terminologia ambígua. Exemplo disso, segundo a autora, é utilizar o "individualismo interativo" para denominar a visão de Friedrich Hayek para o problema da ordem social, uma nova abordagem de individualismo metodológico. $\mathrm{O}$ individualismo interativo "se diferencia do individualismo metodológico convencional - que deduz a ordem de escolhas racionais de indivíduos - sob dois aspectos principais. O primeiro diz respeito à problematização das condições de conhecimento - ou seja o conhecimento dos indivíduos não é suposto como dado ou objetivamente disponível, mas como o primeiro problema a ser enfrentado pela abordagem. O segundo, decorrente do primeiro, diz respeito à própria unidade de análise que já não mais pode ser os indivíduos isolados, tomados como dados, mas 'indivíduos interagentes'” (Kerstenetzky, 2007, p. 101). 
analisa o indivíduo no âmbito da ontologia e pretende apresentar algumas contribuições no campo da chamada "Economia Social" (Social Economics).

A Economia Social entende o indivíduo como um ser social, cuja ontologia só pode ser construída a partir de sua dimensão intrinsecamente social. Essa concepção de indivíduo envolve pelo menos dois desafios ontológicos, não necessariamente isolados. O primeiro é o de como explicar a individualidade (ou seu grau) quando o indivíduo é concebido a partir de seu processo totalizante de imersão social. $O$ segundo advém da possibilidade de o indivíduo e suas múltiplas relações sociais gerarem seres sociais com múltiplas individualidades e/ou identidades.

Por mais que a ênfase concedida ao indivíduo mude conforme o aparato teórico e metodológico, as identidades possuem relação com o estudo dos indivíduos e aproximam-se da ontologia. "[...] In economics today individuals can be single persons, groups of people and the different selves of single persons" (Davis, 2006, p. 371). No campo da Economia mainstream, George Akerlof e Rachel Kranton (2000) difundiram o tema identidades, mas em uma base utilitária neoclássica. Outro autor que utiliza o conceito de identidades sociais na Economia é James March (1994), porém aborda apenas os elementos sociais dos indivíduos e as identidades como sinônimo de papéis sociais.

O conceito de identidade social de John Bryan Davis, por outro lado, amplia teoricamente a concepção de indivíduos e suas identidades. Para Davis (2006), a identidade social é a união das identidades individual e pessoal; permite incorporar na construção ontológica do indivíduo os aspectos cognitivos, sociais e institucionais a partir de uma perspectiva evolutiva e histórica. A concepção de indivíduo e sua (re)identificação social ao longo do tempo incorporam questões de natureza normativa, como: justiça, direitos humanos, democracia, entre outras.

Apesar de March, Akerlof e Kranton trazerem à tona a discussão das identidades, os conceitos e as abordagens diferem entre si, como ocorre com a definição do termo "identidade social". Enquanto que para esses autores e outros presentes na literatura, como Amartya Sen, Alan Kirman e Miriam Teschl, a identidade social pertence aos condicionamentos sociais, às categorias sociais e aos contextos socialmente criados, Davis, como será apresentado ao longo do artigo, traz avanços nesta definição principalmente com a distinção entre identidades social, individual e pessoal.

O objetivo deste artigo é apresentar a abordagem ontológica do indivíduo na Economia por meio do conceito de identidade social de John B. Da- 
vis e da sua diferenciação com as abordagens de outros autores que também trabalham com as identidades na Economia, como Akerlof e Kranton, March, Sen, e Kirman e Teschl. ${ }^{2} \mathrm{O}$ artigo introduz o estudo dos indivíduos e das identidades na Economia (seção 2), em seguida apresenta a abordagem das identidades para Akerlof e Kranton (seção 3) e as contribuições de outros autores: March, Sen, Kirman e Teschl (seção 4). Na sequência, é exposta a temática das identidades de Davis (seção 5) e, por fim, são feitas algumas considerações.

\section{Indivíduo e identidades na Economia}

estudo dos indivíduos na Economia teve, ao longo do tempo, restrita atenção. "Economics, in fact, takes the individual as given, and operates on the implicit assumption that one particular conception of the individual, indeed one of well-established lineage - the subjectivist view - successfully explains individuality" (Davis, 2003, p. 1). Ou seja, o indivíduo, na Economia tradicional, é dado, sem qualquer análise ou aprofundamento, e sua individualidade era considerada apenas do ponto de vista singular.

A Economia tradicional, segundo Davis (2003), possui algo parecido com as identidades pessoais quando, implicitamente, segue as identidades numa abordagem filosófica. Conforme o autor, isso ocorre, pois, tanto numa perspectiva tradicional da Economia quanto na Filosofia, as iden-

2 Diferente da abordagem de Davis, existem outras linhas de pesquisas recentes na área de Economia que priorizam o estudo dos mercados. Mirowski (2007), com a teoria dos Markomatas, e Gode e Sunder (1993), com a modelagem de agentes computacionais de Inteligência Zero (ZI), apontam que o estudo dos indivíduos viria em um segundo plano, a favor do estudo a priori dos mercados. O primeiro autor utiliza a Economia computacional e considera os mercados como algoritmos (chamados de markomatas, ou "mercatômatos"). Na mesma linha, Gode e Sunder (1993) apresentam experiências de mercado em que os comerciantes humanos são substituídos por programas de ZI, sem considerar os processos cognitivos dos indivíduos. Gode e Sunder (1993) justificam que seus resultados auxiliam nas previsões da teoria econômica neoclássica, uma vez que pressupõem agentes maximizadores de utilidade como forma de derivar equilíbrios do mercado. Ou seja, em ambos os casos, o estudo dos indivíduos é condicionado ao estudo dos mercados - ignora-se o fato de os mercados serem formados por indivíduos. Diferente disso, o argumento principal do presente artigo segue Davis (2003) que concede papel central para o estudo dos indivíduos na Economia. Segundo ele, a teoria econômica tradicional não faz considerações sobre o indivíduo, suas relações e suas reidentificações, apenas o trata como um agente, assim como seria o caso de uma empresa ou um governo - que são formados por pessoas. Para Davis (2009) é preciso construir uma teoria em que tanto os contextos e as estruturas sociais quanto os indivíduos sejam considerados de forma integrada. 
tidades individuais possuem um caráter "imutável", isto é, apesar de os indivíduos mudarem com o passar do tempo, eles continuam sendo as mesmas pessoas, com o mesmo corpo humano, com o mesmo cérebro. "This implies that it should be possible to say what explains, or at the very least say what is believed to explain, individual identity in economics" (Davis, 2003, p. 12). No entanto, para Davis (2003), por mais que a Economia traga implicitamente este tema, esta ciência, diferente da Filosofia, não discute o problema da "reidentificação" da identidade pessoal. Segundo o autor, essa preocupação com a reidentificação implica em acompanhar o indivíduo e as mudanças que ocorrem com o passar do tempo.

Para Davis (2003), a maneira como a Economia tradicional enxerga os indivíduos, como meros agentes econômicos, não considera as diferenças e as individualizações. O problema está em fazer a distinção entre os indivíduos e individualizá-los - indivíduos independentes uns dos outros. Davis (2003) chama isso de problema da "individuação". Assim, uma importante diferenciação entre a Economia tradicional, por vezes chamada de Economia ortodoxa, e as visões alternativas e críticas, denominadas de Economia heterodoxa, está nas concepções sobre o indivíduo (Davis, 2003).

Conforme Davis (2003), a "Economia Ortodoxa" concede grande ênfase para o indivíduo e divide-se em três escolas de pensamento: Economia Neoclássica, Economia Maistream Contemporânea e Economia Austríaca. As duas primeiras escolas, segundo o autor, consideram o indivíduo como autônomo e "atomizado", e a última escola, principalmente na visão de Hayek, considera o indivíduo como um ser autônomo, mas essa autonomia não implica em ausência de interações sociais. ${ }^{3}$ A Economia Ortodoxa pode também ser entendida pela figura do que Davis (2003) chama de "indivíduo internalista" o que caracteriza o "individualismo metodológico" dessa linha de pensamento. A "Economia Heterodoxa", por outro lado, concede menor peso para os indivíduos e os considera como imersos aos contextos sociais - "indivíduos externalistas" - e segue o chamado "holismo metodológico" (Davis, 2003).

Dessa forma, Davis (2003) conclui que a Economia Neoclássica e a Economia Maistream Contemporânea não apresentam uma concepção adequada de indivíduo, e que, diferente disso, a Economia Heterodoxa apresenta elementos adequados para uma teoria dos indivíduos. Com essas 
duas considerações, a Economia deveria ser entendida tanto num quadro explicativo quanto de causa e efeito; "it would demonstrate that the individual can remain a primary normative focus in spite of being socially embedded" (Davis, 2003, p. 17).

A ilusão de muitos economistas tradicionais é, conforme Hodgson (2013), explicar fenômenos econômicos com base em indivíduos unicamente isolados. Enquanto que a Economia neoclássica desconsidera o indivíduo em sociedade e reforça a existência do "individualismo metodológico", alguns cientistas sociais, por outro lado, explicitam a socialização do indivíduo e negligenciam os aspectos biológicos e cognitivos (Hodgson, 2013).

Ao admitir a importância do elemento social na formação dos indivíduos, as particularidades individuais não são ignoradas. Ao distanciar-se da crença hedonista ${ }^{4}$ de indivíduo, não se pretende afirmar que os indivíduos não são egoístas, mas que esta característica humana é verificada em algumas situações e, ao mesmo tempo, conecta-se com preceitos morais e sociais.

Hodgson (2002) enfatiza que as explicações não ocorrem apenas em termos de indivíduos ou instituições, ambos não possuem o mesmo status ontológico. Os atores individuais e as estruturas sociais não são ontologicamente simétricas. Um caminho nessa discussão, conforme Hodgson (2013), é resgatar o estudo sobre o indivíduo, como faz Davis (2003), pesquisador da Economia Social, que apresenta estudos recentes sobre a teoria do indivíduo na Economia com base no conceito de identidades.

Com a necessidade de avançar nos estudos sobre indivíduos na Economia, para modificar a ideia de "individualismo" e considerar os elementos sociais, individuais e institucionais, a Economia Social ganha espaço central. Para Davis e Dolfsma (2008), a Economia Social, no sentido de economia de um país, e não como ciência, refere-se a um terceiro setor da economia de mercado, em que prevalecem relações cooperativas e sem fins lucrativos. No entanto, conforme os mesmos autores, a Economia Social, como parte da Ciência Econômica, preocupa-se com o funcionamento

4 Para Veblen (1898, p. 389), "the hedonistic conception of man is that of a lightning calculator of pleasures and pains, who oscillates like a homogeneous globule of desire of happiness under the impulse of stimuli that shift him about the area, but leave him intact. He has neither antecedent nor consequent. He is an isolated, definitive human datum, in stable equilibrium except for the buffets of the impinging forces that displace him in one direction or another". 
da economia; inclui valores e relações sociais. ${ }^{5}$

Embora seja constituída por diferentes linhas teóricas e analíticas, a Economia Social, na visão de Davis e Dolfsma (2008), possui duas principais linhas de pesquisa. A primeira inclui estudos sobre as formas de produção e organização que não são regidas pela lógica pura do mercado, nem da esfera pública. A segunda linha de pesquisa resgata a importância dos valores e das relações sociais (lato sensu) para melhor compreensão teórica do próprio mercado econômico. Diferentemente da definição tradicional de Economia - "a ciência da alocação de recursos escassos" -, esta, na abordagem da Economia Social, pode ser concebida como a "ciência do provimento", isto é, uma ciência que explica como as pessoas organizam-se em sociedade para produzir e satisfazer suas necessidades (Davis; Dolfsma, 2008).

Apesar de diferentes conceitos e níveis de abrangência, a Economia Social volta-se para o funcionamento das relações sociais, da ética e dos valores, ou seja, volta-se para como os indivíduos relacionam-se e comportam-se em sociedade (Davis; Dolfsma, 2008). Para Davis e Dolfsma, a Economia faz parte de um aparato social, composto de relações sociais e valores, de modo que é restrito o pensamento econômico tradicional de um indivíduo maximizador, autônomo e ausente de interações sociais.

As identidades são estudadas com mais força na Sociologia, Psicologia, Filosofia, Antropologia e, mais recentemente, na Economia.

Because of its explanatory power, numerous scholars in psychology, sociology, political science, anthropology, and history have adopted identity as a central concept. This paper shows how identity can be brought into economic analysis, allowing a new view of many economic problems. If economics now addresses identity, it surely has the capacity to address more or less everything across the social sciences since identity, however understood and determined, underpins all action. (Akerlof; Kranton, 2000, p. 716).

Assim, ao perpassar por diferentes ciências, as identidades trazem distintas formas de abordagens. Enquanto que para Davis, as identidades, assim como os valores, são construídas no centro das relações sociais e individuais, formam "quem são os indivíduos" - base ontológica -, outros autores utilizam o termo com significados distintos.

George Akerlof e Rachel Kranton (2000) trouxeram as primeiras contribuições nesta temática por meio da definição de identidades em um

5 Existe também uma diferenciação entre a "abordagem socioeconômica" e a Economia Social. Para Davis e Dolfsma (2008, p. 4), "while both social economics and socio-economics emphasize the role of values in the economy, socio-economics takes a more Kantian perspective". 
quadro neoclássico padrão, como um argumento na função de utilidade maximizadora (Davis, 2007).

\section{Identidades na visão de Akerlof e Kranton}

Davis (2007) classifica autores, como Akerlof e Kranton, em uma nova linha de pesquisa sobre identidades que está se desenvolvendo na Economia, chamada de "Economia recente". Esta inclui um conjunto de novos programas de pesquisa que surgiram nas últimas duas décadas com contribuições de outras ciências - Psicologia, Sociologia e Filosofia - como tentativa de apresentar avanços em relação à abordagem tradicional neoclássica. No entanto, conforme Davis (2007), por mais que Akerlof e Kranton pertençam a essa agenda de pesquisa "recente" sobre Economia e identidades, pois inseriram um novo conceito que não é de natureza econômica, a "autoimagem", estes autores não rompem completamente com aspectos neoclássicos, pois perpetuam a análise utilitária. ${ }^{6}$

$\mathrm{Na}$ função de utilidade proposta por Akerlof e Kranton (2000), a identidade está associada a categorias sociais e afeta o comportamento dos indivíduos. No entanto, embora reconheçam que as escolhas dos indivíduos estão imersas no meio social, os autores ainda assumem o postulado da exogeneidade das preferências, o que limita a explicação de como as identidades sociais mudam no tempo.

Akerlof e Kranton (2005) reconhecem as limitações da abordagem neoclássica padrão da Economia, em que consta que as preferências dos indivíduos são fixas e a utilidade depende apenas de valores monetários. Esses autores trazem avanços para a Economia no que se refere à concepção neoclássica tradicional ao considerar que as funções de utilidade podem se alterar com o tempo devido às mudanças nas normas de comportamento. "Indeed, norms are taught - by parents, teachers, professors, priests, to name just a few. Psychologists say that people can internalize norms; the norms become their own and guide their behavior" (Akerlof; Kranton, 2005, p. 12). Os autores afirmam que o termo "identidades" pode ser usado para: i) descrever um indivíduo com base em categorias sociais como: gênero, cor, função que exerce, etc.; ii) descrever a "autoimagem" de uma pessoa.

6 Preocupados também em manter as raízes neoclássicas, Gode e Sunder (1993) utilizam modelos para analisar o comportamento dos agentes econômicos e de equilíbrios de mercado. 
No entanto, apesar de citar a "autoimagem" no estudo das identidades, Akerlof e Kranton não avançam nesse tópico e acabam considerando que as imagens formadas por cada indivíduo sobre si mesmo também são condicionadas às categorias e às normas constituídas no meio social. "In a model of utility, then, a person's identity describes gains and losses in utility from behavior that conforms or departs from the norms for particular social categories in particular situations" (Akerlof; Kranton, 2005, p. 12). Ou seja, os aspectos pessoais e individuais são ignorados.

Na percepção de Akerlof e Kranton (2005), a identidade inclui a forma como os indivíduos pensam sobre si e como as outras pessoas o classificam. Para os autores, normalmente essa classificação, como gênero e raça, é dada, sendo que existem outras formas de identidades. Exemplo disso é o indivíduo identificar-se como membro de uma respectiva categoria social e passar a comportar-se de acordo com os demais integrantes, com as normas e os objetivos desse grupo. É por isso que o termo identidade, na visão de Akerlof e Kranton, está combinado com categorias sociais, normas e ideais, de modo que a utilidade do indivíduo varia conforme a situação em que se encontra. "Identity describes one special way in which people frame their situation" (Akerlof; Kranton, 2005, p. 13).

Akerlof e Kranton (2005) estudam as identidades por meio de dois modelos que consideram o funcionário de uma organização como membro desta (identificação). ${ }^{7}$ No primeiro modelo de Akerlof e Kranton, de agente-principal simples, há relação entre as identidades dos funcionários e as variáveis econômicas tradicionais (salário). Neste caso, um trabalhador que se identifica com sua empresa exige, por exemplo, menos pagamentos de recompensas.

No segundo modelo, Akerlof e Kranton (2005) descrevem que existem possíveis compensações na política de supervisão. Se, por um lado, a existência de um supervisor rígido da organização para relatar as ações dos trabalhadores permitiria o pagamento adequado para cada esforço de trabalho, por outro lado, isso representaria menor identificação dos funcionários com a organização, por conta da excessiva supervisão. Ou seja, nesse caso, os funcionários exigiriam recompensas maiores para executarem seus trabalhos aos olhos do supervisor (Akerlof; Kranton, 2005). De qualquer forma, essa abordagem de Akerlof e Kranton considera que o uso 7 Conforme Akerlof e Kranton (2005, p. 13), "a basic economic model would have a worker's utility depend on income and effort, with no relation to how she thinks of herself as a member of the firm". 
das identidades permite muitas análises nas organizações que vão além dos incentivos financeiros, tais como: aprimorar modelos de gestão, analisar fusões, etc.

Akerlof e Kranton (2010, p. 4) afirmam que, "in every social context, people have a notion of who they are, which is associated with beliefs about how they and others are supposed to behave". Não é discutivel a importância do contexto social no estudo do comportamento dos indivíduos, mas o problema está em vincular o termo "identidade" como algo relacionado unicamente às regras, aos papéis sociais e às categorias, como foi feito por Akerlof e Kranton.

A abordagem de Akerlof e Kranton não trata das identidades no sentido de analisar "quem é" o indivíduo que trabalha em uma empresa e quais são os seus componentes pessoais e sociais; apenas constata que os trabalhadores normalmente identificam-se com um grupo de funcionários e que o bom desenvolvimento da empresa também decorre da identificação dos empregados com os proprietários ou gerentes desta empresa. As identidades são medidas com base em um modelo de utilidade em que cada identidade é apresentada para um certo nível ideal de esforço, de modo que a utilidade dos trabalhadores cai quando os seus esforços se desviam de seus ideais (Akerlof; Kranton, 2008). Ou seja, a abordagem das identidades desses autores não leva em conta quem realmente é esse indivíduo trabalhador, quais as suas particularidades, mas apenas considera a sua identificação com o grupo de pessoas que compõe a empresa.

Seguindo esta lógica, não são apenas os elementos pecuniários que farão com que os indivíduos se comportem de uma determinada forma em uma empresa, exército de um país ou escola, mas também a maneira como essas pessoas se identificam com a organização em que atuam, ou seja, com as funções que exercem e com os seus superiores (Akerlof; Kranton, 2005). No modelo de identidade estudado por Akerlof e Kranton (2005), os funcionários podem ter identidades que impliquem em maior ou menor proximidade com os objetivos das organizações na qual fazem parte, e isso poderá resultar no grau de sucesso da empresa.

Ao difundir o termo "identidades", os estudos de Akerlof e Kranton trouxeram grandes contribuições para a Economia, principalmente com a publicação do livro "Identity Economics", em 2010. Já no início do livro, Akerlof e Kranton (2010) trazem o exemplo do preconceito de gênero (uma categoria) no trabalho como uma ilustração do que seria "a economia da identidade". Para os autores, regras criadas socialmente sobre como, 
por exemplo, uma mulher deve se portar no trabalho, são internalizadas na mente humana e provocam certos comportamentos "padrões".

A identidade é considerada por Akerlof e Kranton como um atributo comum entre os indivíduos, que emerge de práticas uniformes e que cabe ao indivíduo escolher (Fine, 2009). Para Akerlof e Kranton (2000, p. 717),

[...] because identity is fundamental to behavior, choice of identity
may be the most important "economic" decision people make. Indi-
viduals may-more or less consciously-choose who they want to be.
Limits on this choice may also be the most important determinant of
an individual's economic well-being. Previous economic analyses of,
for example, poverty, labor supply, and schooling have not considered
these possibilities.

No entanto, para Fine (2009), a complexidade da identidade é deixada de lado na análise de Akerlof e Kranton. Ocorrem situações em que os indivíduos não são completamente livres para escolher as suas identidades; existem, por exemplo, pressões sociais para seguir certos padrões da sociedade. Da mesma forma, não é passível de escolha o fato de nascer em certas condições sociais ou culturais. Neste sentido, Akerlof e Kranton não descrevem como as relações sociais auxiliam na formação das identidades e dos valores dos indivíduos e não trazem os aspectos ontológicos da identidade, da mesma forma que as abordagens de outros autores, como March, Kirman e Teschl, que serão vistas na seção seguinte.

Apesar de Akerlof e Kranton (2010) admitirem que iniciaram os estudos sobre identidades na Economia por volta de 1995, eles afirmam que isso já estava sendo estudado antes, mas por meio dos "gostos". ${ }^{8}$ Conforme os autores, os gostos são influenciados pelo contexto social e, da mesma forma, as identidades derivam das concepções formadas socialmente.

Para Akerlof e Kranton (2010), o estudo das identidades na Economia introduz o elemento social nas análises sobre as decisões dos indivíduos. "Identity Economics, in its turn, brings in social context - with a new economic man and woman who resemble real people in real situations" (Akerlof; Kranton, 2010, p. 7). Ainda, nas palavras de Akerlof e Kranton (2010, p. 13), "people's identity defines who they are-their social category. Their identity will influence their decisions, because different norms for behavior are associated with different social categories".

No entanto, identidade é muito mais que meramente um gosto, uma 8 Nas palavras de Akerlof e Kranton (2010, p. 6): "quite possibly, we thought, identity was already captured in the economics of the time; perhaps it was already included in what we call tastes". 
preferência ou uma categoria constituída socialmente. $\bigcirc$ estudo das identidades envolve, na verdade, o estudo de quem é o indivíduo, o que não inclui apenas categorias e regras formadas no contexto social.

Akerlof e Kranton (2000) utilizam bases psicológicas ao considerar a identidade social como uma "autoimagem" do indivíduo, e que esta é formada por categorias socialmente criadas, como: gênero, idade, religião. Esses autores classificam as identidades como sociais devido à identificação dos indivíduos com outros por meio de categorizações. Entretanto, "this effectively foreclosed any analysis of how individuals happened to have particular social identities, or how they might organise their different social identities to create personal identities" (Davis, 2007, p. 360). É justamente neste fato que Davis (2007) aponta uma carência analítica na concepção de Akerlof e Kranton, pois eles não fazem referência às identidades que vão além da identificação social baseada na categorização. Isso exigiria a inclusão das identidades pessoal, individual e social, como propõe Davis.

Para Akerlof e Kranton (2010), a etnia, a cor, o gênero - categorias formam as identidades das pessoas; as regras sociais, no contexto em que os indivíduos fazem parte, interferem nos comportamentos. Da mesma forma que a abordagem de Akerlof e Kranton reforça a identificação social dos indivíduos, outros autores fortalecem a importância de considerar os aspectos sociais que compõem o comportamento humano, como March, Sen, Kirman e Teschl.

\section{Identidades sociais: as contribuições de outros au- tores da Economia}

Além da importante contribuição para a Economia de Akerlof e Kranton sobre identidades baseadas em categorizações, existem autores que discutem as formações sociais no processo de tomada de decisão dos indivíduos, principalmente nas organizações, como é o caso de James March (1994).

Teóricos neoclássicos das organizações, James March e Herbert Simon desenvolveram trabalhos vinculados à temática comportamental com algumas modificações em relação à teoria neoclássica tradicional da Economia (Shafritz; Ott; Jang, 2015, p. 94). March é conhecido principalmente por seu trabalho sobre a teoria comportamental das organizações e por ser 
considerado o "guru dos gurus" das ideias de gestão (The Economist, 2009). Além disso, March traz o termo "papéis ou identidades sociais" para discutir o comportamento dos indivíduos.

Apesar de March (1994) considerar as identidades e os papéis sociais como sinônimos, diferente do que propõe Davis (2009a), traz importantes contribuições sobre a forma como os papéis sociais compõem os indivíduos e de como o comportamento pode ser resultado de normas socialmente criadas. March (1994) chama de "lógica de adequação" (logic of appropriateness $)^{9}$ o fato de os indivíduos comportarem-se conforme três etapas: o reconhecimento da situação, o papel social do indivíduo ou da organização perante um grupo de pessoas, e as regras que permeiam a identidade social.

A "lógica de adequação" possui um componente racional; as pessoas são conscientes do papel ou da identidade social que exercem ou gostariam de exercer (March, 1994). Conforme March e Olsen (2008, p. 690), "following rules of a role or identity is a relatively complicated cognitive process involving thoughtful, reasoning behavior (...)".

A perspectiva da "lógica de adequação", conforme March e Olsen (2008), considera a ação humana motivada por regras "adequadas ou exemplares" de comportamentos.

Rules are followed because they are seen as natural, rightful, expected, and legitimate. Actors seek to fulfill the obligations encapsulated in a role, an identity, a membership in a political community or group, and the ethos, practices, and expectations of its institutions. Embedded in a social collectivity, they do what they see as appropriate for themselves in a specific type of situation. (March; Olsen, 2008, p. 689).

Essas regras de comportamento são constituídas socialmente e são incorporadas pelos indivíduos por meio de papéis e identidades sociais. Ou seja, conforme March e Olsen (2008), a "adequação" desta lógica refere-se ao fato de os indivíduos se adequarem às práticas institucionalizadas por um grupo social e agirem em conformidade com isso.

The term "logic of appropriateness" has overtones of morality, but rules of appropriateness underlie atrocities of action, such as ethnic cleansing

9 Para March (1994), a racionalidade limitada e processual de Simon é vista numa "lógica da consequência", e a "lógica da adequação" é um avanço na análise de processo de tomada de decisão baseado em heurísticas e identidades. A primeira baseia-se em expectativas sobre as consequências futuras de formação das preferências, a última baseia-se no aprendizado com o passado e na formação de identidades (March, 1994). Apesar de distintas, ambas utilizam-se de regras e da razão (pensamentos e julgamentos). 
and blood feuds, as well as moral heroism. The fact that a rule of action is defined as appropriate by an individual or a collectivity may reflect learning of some sort from history, but it does not guarantee technical efficiency or moral acceptability. (March; Olsen, 2008, p. 690).

Os papéis sociais trazem à tona o caráter emulativo do comportamento humano e compõem as identidades dos indivíduos, que podem sofrer alterações e passar pela aprendizagem no decorrer do tempo. Conforme March (1994), a racionalidade dos indivíduos é composta de normas seguidas por grupos de pessoas, e as identidades são fundamentais para entender o comportamento. "From this perspective, any decision in any context can be seen as being shaped by identities and a logic of appropriateness" (March, 1994, p. 59).

As identidades e as regras estão presentes, conforme March (1994), nas organizações, como: trabalhadores de um determinado setor da empresa, médicos de um hospital, professores de um departamento, etc. Estas regras organizacionais ditam certos padrões de comportamento e compõem o que seria uma decisão "esperada" pelo grupo (March, 1994). Exemplo disso é o caso de um indivíduo que, apesar de gostar de roupas esportivas, pode ter seu comportamento de consumo de vestuário modificado quando passa a integrar o grupo de professores de um determinado centro universitário, em que as pessoas vestem-se de maneira mais formal. Ou seja, mesmo que não exista uma regra formalmente escrita que exija o uso de um estilo de roupa, o ambiente a que o professor está vinculado compõe-se também de regras informais (padrões de comportamentos esperados) que constituirão um papel social e modificarão seu comportamento.

As identidades/papéis sociais, para March (1994), possuem três características essenciais: i) descrevem, por exemplo, o que é ser um profissional (professor, contador, médico, etc.) por meio da criação de "rótulos" que distinguem as pessoas; ii) são aceitas em troca de algo que os indivíduos valorizam, tanto financeira quanto sentimentalmente (melhorar a autoestima, ganhar prestígio, etc.); iii) indicam o que é "verdadeiro, bom e moralmente correto" do ponto de vista da sociedade, e interferem na consciência e nas emoções dos indivíduos. As pessoas são caracterizadas como "corretas", desde que sigam certas rotulações. "The individual self is drawn using social templates" (March, 1994, p. 64).

Para March (1994), além das identidades resultarem de processos sociais, elas também remetem à individualidade de cada ser, o que faz uma pessoa diferenciar-se das demais e possuir as suas convicções e experiências de vida. 
Individuals adopt rules of behavior from families, schools, religious groups, age cohorts, and companies. They build their own understandings of themselves using socially based distinctions. As collections of individuals define and solve problems posed by their environments, they develop shared rules for behavior and shared attitudes toward experience. Those rules and attitudes are organized in terms of social roles or identities from which individual identities are formed. (March, 1994, p. 63-64).

Os indivíduos possuem múltiplas identidades e elas são formadas por fatores externos e internos ao indivíduo, por regras, emoções, aprendizagens e experiências. Para March (1994), os indivíduos possuem diversos papéis sociais; uma pessoa não está apenas na figura de uma professora, ela também é uma mãe, uma amiga, uma dona de casa, etc. Esta integração de papéis exige coerência no cumprimento de tarefas, mas pode haver conflito em qualquer momento (March, 1994). Ao mesmo tempo em que espera-se que uma mãe seja amorosa com seus filhos, ela precisa ser firme e decidida ao tomar uma decisão em seu trabalho.

Defining a role or identity and achieving it require time and energy, thought and capability. In order to understand the impact of rules upon action, we need to study such (imperfect) processes as attention directing, interpretation of rules, the validation of evidence, codification of experiences into rules, memory building and retrieval, and the mechanisms through which institutions distribute resources and enable actors to follow rules, across a variety of settings and situations. (March; Olsen, 2008, p. 694).

Conforme os processos mentais, as regras e o contexto no qual o indivíduo está inserido, determinados papéis ou identidades são sinalizados. March (1994) aponta para a existência de quatro mecanismos psicológicos comuns entre as identidades/papéis sociais e as regras: i) aprendizagem experimental: as pessoas aprendem a usar certas identidades em determinadas situações; ii) categorização: os indivíduos respondem às situações conforme conceitos fundamentais da identidade que vêm à mente rapidamente; iii) recência: identidades e regras recentemente utilizadas são mais propensas a serem repetidas; iv) contexto social dos outros: quando uma situação envolve outras pessoas, mudam-se as identidades e as regras que serão usadas para tomar decisões. Neste último caso, quando a decisão envolve outras pessoas, elementos de equidade e justiça vêm à mente, assim como as diferenças entre os indivíduos se sobressaem (uma única pessoa é notada como "mais jovem" principalmente em meio a um grupo de pessoas "mais velhas") (March, 1994).

Conforme March e Olsen (2008), as regras, as instituições e as identidades fornecem parâmetros ou mecanismos para estudar as ações dos 
indivíduos e não apontam para um único comportamento. $\mathrm{Na}$ opinião desses autores, o estudo do comportamento humano baseado nas regras e identidades faz com que seja necessária a investigação desses mecanismos que permitem a evolução e a legitimidade das regras e das identidades, tais como: a história, a aprendizagem e a seleção. "Key behavioral mechanisms are history-dependent processes of adaptation such as learning or selection" (March; Olsen, 2008, p. 696). Além disso, as regras influenciam a ação dos indivíduos apenas em parte, pois existem outros fatores que compõem o comportamento, como os hábitos, as emoções e os cálculos de utilidade esperada, o que fornece uma ampla gama de pesquisas na área.

Apesar dos aspectos sociais serem importantes e mais facilmente perceptíveis, March (1994) reduz o conceito de identidades sociais na figura dos papéis sociais. Por esse motivo, o autor concede espaço apenas para os elementos sociais no comportamento, sem fazer referência aos fatores pessoais. Da mesma forma, Akerlof e Kranton (2000) utilizam a definição de identidades sociais apenas para considerar a identificação do(s) indivíduo(s) com outro(s) via categorias socialmente criadas, sem considerar as instituições, as relações sociais, a autoimagem e a personalidade de cada pessoa.

Outro autor que, ao estudar identidades, reforça o aspecto social é Amartya Sen. Sen (2007), em seu livro Identity and Violence, afirma que o indivíduo possui múltiplas identidades simultaneamente ou ao longo do tempo. $O$ autor apresenta a abordagem das identidades de forma vinculada às categorias socialmente criadas.

And yet history and background are not the only way of seeing ourselves and the groups to which we belong. There are a great variety of categories to which we simultaneously belong. I can be, at the same time, an Asian, an Indian citizen, a Bengali with Bangladeshi ancestry, an American or British resident, an economist, a dabbler in philosophy, an author, a Sanskritist, a strong believer in secularism and democracy, a man, a feminist, a heterosexual, a defender of gay and lesbian rights, with a nonreligious lifestyle, from a Hindu background, a non-Brahmin, and a nonbeliever in an afterlife (and also, in case the question is asked, a nonbeliever in a "before-life" as well). This is just a small sample of diverse categories to each of which I may simultaneously belong - there are of course a great many other membership categories too which, depending on circumstances, can move and engage me. (Sen, 2007, p. 19).

Conforme Sen (2007), as identidades possuem algumas características: i) elas são plurais e uma não se sobrepõe ou elimina a outra; ii) as pessoas fazem escolhas, explícita ou implicitamente, sobre a importância concedi- 
da para cada identidade. Sen (2007) concorda que se deve levar em conta a identificação de uma pessoa com outras, mas alerta para dois tipos comuns de reducionismos: i) âmbito econômico: ignorar totalmente o estudo das identidades (identificação própria e com os outros); ii) âmbito social: as pessoas são unicamente condicionadas e filiadas aos grupos sociais.

De acordo com Davis (2006), Sen traz à tona o estudo das identidades por meio do termo commitment. Conforme Sen (2004, p. 214), o termo commitment possui várias interpretações, mas basicamente volta-se para uma diferente forma de comportamento em que há o rompimento da visão tradicional na Economia que liga o bem-estar individual - com ou sem simpatia - com a escolha da ação. "But commitment can also involve violation of self-goal choice, since the departure may possibly arise from self-imposed restrictions on the pursuit of one's own goals (in favor of, say, following particular rules of conduct)" (Sen, 2004, p. 214).

Davis (2006) descreve que essa maneira de Sen compreender as identidades leva em conta que o indivíduo é um ser capaz de agir de maneira autointeressada - capacidade de raciocínio próprio - mas também de pensar sobre outros elementos que envolvam o(s) outro(s). Em outras palavras, é o comportamento baseado no comprometimento do indivíduo consigo, mas principalmente com o(s) outro(s). Neste sentido, a visão de Sen (2004) retrata que o aspecto social está fortemente ligado à maneira como o indivíduo se comporta e se identifica.

Atualmente, Sen (2015) questiona a forma de unificar as identidades pessoais e sociais em uma mesma terminologia, como o caso de "identidades globais", uma vez que essas identidades são diferentes: i) a identidade pessoal envolve a identificação da própria pessoa (quem ela era e como ela é hoje); ii) a identidade social enfatiza a identificação social (pertencimento a grupos e categorias sociais).

A crítica de Sen (2015) é entender a identidade pessoal e a identidade social como "partes de um todo". Na verdade, para o autor, essas partes são muito diferentes e não podem ser ofuscadas pelo todo. Falar apenas em identidade social é condicionar o indivíduo a uma nacionalidade, uma religião, um partido político, de modo que o indivíduo deixa de ser quem é para atender a um critério social (Sen, 2015).

Em outras palavras, para Sen (2015), trazer um conceito que unifique a identidade pessoal da social é transmitir a ideia de que um indivíduo deixa de ser quem ele é e passa a ser apenas um grupo, diferente do que propõe 
a identidade pessoal, que apesar do indivíduo mudar com o tempo, ele não deixa de ser quem ele é; ele não perde suas particularidades.

What is, however, not clear to me is how this is at all combinable with social identity, which reflects our affiliations with social groups. We can change many of our affiliations, including extremely important ones, but that would not make us a different person. The demands of personal identity would seem to me to be not only different from, but also irreconcilable with the priorities of social identity. (Sen, 2015, p. 286).

O incômodo de Sen (2015) está em considerar a identidade como um agregado de aspectos pessoais e sociais e ignorar a individualidade de cada ser, o que demonstra ser uma abordagem superior à de Akerlof e Kranton e de March. De acordo com Davis (2006), enquanto que Akerlof e Kranton possuem uma abordagem neoclássica e Sen possui a abordagem do commitment, Kirman e Teschl caracterizam-se pela abordagem da complexidade.

Kirman e Teschl (2006) também discutem identidades e complementam a abordagem de Akerlof e Kranton, de March e de Sen. Os autores trabalham com as identidades trazendo a ideia de que as motivações para as escolhas dos indivíduos não devem ser totalmente dissociadas de elementos de bem-estar. Por mais que Kirman e Teschl (2006) tragam importantes contribuições sobre as escolhas e preferências dos indivíduos com o intuito de modificar as visões de maximização de utilidade e de autointeresse presentes na Economia tradicional, eles não discutem identidades num plano ontológico.

However, our basic theme in this article is that if choices contribute to a person's well-being, then we need to be able to distinguish whether the origin of those choices is predominantly based on her 'social identity', omitting individual, self-interested motivations, or the result of this individual's 'personal' identity that includes accepted values of his or her social environment. (Kirman; Teschl, 2006, p. 303).

Mesmo que Kirman e Teschl apresentem um tópico para discussão filosófica, eles entendem as identidades, assim como Sen (2015), apenas como: i) sociais, que levam em conta o contexto social; e ii) pessoais, que consideram as características de cada pessoa. Os autores trazem contribuições quando introduzem considerações filosóficas ao abordar as identidades pessoais. Para Kirman e Teschl, a definição de identidade pessoal é complexa pois inclui características pessoais que se alteram com o passar do tempo, como a memória e o corpo, apesar de referir-se ao mesmo indivíduo. Nessa interpretação, os indivíduos possuem múltiplos "eus", o que 
promove uma visão dinâmica para as identidades. ${ }^{10}$

Essa ideia dinâmica das identidades pessoais está na identificação do indivíduo com outros grupos de pessoas, de modo a provocar mudanças nas características próprias e na forma de como cada pessoa gostaria de ser. As identidades são mutáveis, pois as pessoas e os grupos de identificação se alteram com o passar do tempo; o mesmo ocorre com as preferências dos indivíduos (Kirman; Teschl, 2006).

Os autores contribuem com a abordagem das identidades por meio dessa concepção dinâmica, mas focam nas escolhas e preferências com o intuito de superar a concepção de agente econômico tradicional e diferenciarem-se das abordagens de Akerlof e Kranton e de Sen.

[...] We could say that both approaches, Akerlof and Kranton's as well as Sen's approach to identity have proposed viewing the economic agent as having purely selfinterested preferences as well as identity-related preferences (or preference orderings, based on some social values for example). While the former approach implies that people can always come up with a complete ordering by subsuming everything to broadly defined selfinterest and by weighting and 'trading off' individual and identity-related preferences, the latter claims that this may not always be the case, people remain undecided about the two and not everything is chosen for one's self-interest, however broadly it might be defined. Consequently, the former approach claims that a person makes her best choice, while the latter questions this and holds that people make a maximal choice by choosing according to either one or the other. However, the first approach suffers from the weakness that we do not know whose self's best choice we are dealing with - the individual's self(-interest) or the society's interest in the individual. The second approach on the other hand lacks an account of the nature of the values that guide people's maximal choices and of the reason why a person finally chooses one or the other of their options. Both approaches therefore account for situations in which it might be rational for individuals to act against their own "narrowly defined selfinterest". (Kirman; Teschl, 2006, p. 313-314).

Para Kirman e Teschl (2006), podem existir situações em que não há autointeresse nas escolhas, mas também podem ocorrer mudanças na própria pessoa (autoimagem), que podem passar a agir diferente de concepções socialmente criadas. As escolhas e as preferências se alteram, as imagens idealizadas

10 "For the complex and dynamic view, we need an account of identity with an underlying basis that can itself be modified. This brings us to our view of identity where people choose to belong to social groups in order to become who they want to be and to realise their self-image. But the dynamics should be ongoing. By choosing their social group, people know that they will change what they are right now in order to become who they would like to be. Indeed, the social group is an instrument for people to acquire those characteristics they would like to have. However, people in our model will not necessarily remain tied to their choices of social groups because these groups may themselves change over time. Ultimately, of course, who they want to be might also change as a consequence of their search for identity" (Kirman; Teschl, 2006, p. 304). 
de identificações pessoais modificam-se, as pessoas mudam e nem sempre agem da maneira como é "esperada". Assim, segundo Kirman e Teschl (2006), é preciso elaborar modelos para o estudo das identidades que compreendam a relação entre as escolhas e a maneira como o indivíduo se identifica.

No entanto, uma visão dinâmica da identidade impede que se estabeleça um modelo estático, e isso não diminui a importância analítica de uma abordagem. Davis (2010), ao apreciar a complexidade da dinâmica da individuação e da endogeneidade de processos sociais, contesta tentativas de modelar e de generalizar identidades. ${ }^{11}$ De acordo com Ross (2012), a rejeição de Davis para modelagens baseadas na utilidade do bem-estar mostra-se a favor de abordagens que considerem as singularidades da espécie humana, o que aproxima-se mais das análises de Sen, mas com uma ressalva: Davis faz uma importante diferenciação entre identidades sociais, individuais e pessoais.

A abordagem da identidade social de Davis (2006) representa uma evolução no estudo do indivíduo na Economia e demonstra-se superior ao que foi destacado por Akerlof e Kranton, March, Sen, Kirman e Teschl, pois considera juntamente com os elementos sociais os fatores individuais e pessoais dos indivíduos, como será visto na próxima seção.

Por mais que Davis se aproxime de Sen, devido ao foco ontológico, a concepção de identidade social é distinta entre os autores. Davis, diferente do que é temido por Sen, não ofusca, no conceito de identidade social, as identidades pessoal e individual. Ao contrário, Davis considera o termo "identidade social" como uma unificação das identidades pessoal e individual, sendo que uma definição não é redutível à outra.

\section{Identidades na Economia: as contribuições de John B. Davis}

Pesquisador da chamada "Economia Social", John Bryan Davis, graduado em Filosofia e doutor em Filosofia e em Economia, desenvolve trabalhos

11 Exemplo disso foi Horst, Kirman e Teschl (2007), que não introduzem no modelo de determinação de identidade a deliberação endógena, devido à dificuldade de teorizar isso matematicamente. Também utilizando modelos, Bénabou e Tirole (2011) desenvolveram uma teoria do comportamento moral, individual e coletivo por meio de modelo geral de identidade em que as pessoas se preocupam com "quem elas são" e identificam seus valores com base em escolhas passadas. 
sobre metodologia, indivíduos e identidades na Ciência Econômica. $\bigcirc$ estudo atual sobre indivíduos na Economia é visto por Davis (2011) como pertencente a uma fase de transição, ${ }^{12}$ em que se deixa de considerar um indivíduo autônomo e isolado para conceder maior espaço para a análise das pessoas e suas relações. Por mais que Davis (2011) referencie essa fase de transição, é importante considerar que novas abordagens já trazem outras concepções do que seria o indivíduo e o individualismo, diferente do "individualismo metodológico" tradicionalmente difundido. Novas abordagens ampliaram a visão de individualismo no sentido de considerar não apenas os indivíduos, mas os indivíduos e também as estruturas/relações sociais (Hodgson, 2007).

Para Davis (2003), na teoria econômica, tradicionalmente difundida nos manuais de Economia, não são feitas considerações sobre o indivíduo; este é apenas um "elemento", isolado de qualquer relação ou influência, ao qual apenas é atribuída uma função de maximização. Essa visão tradicional, que já possui superações e avanços, não considera o ser humano como um indivíduo atuante e formado por fatores cognitivos e institucionais.

Apesar de longos anos de aproximação dos indivíduos aos pressupostos neoclássicos de racionalidade perfeita e maximização de utilidade, outras abordagens comportamentais, institucionalistas e sociais fortalecem-se com a introdução de importantes contribuições para o estudo dos indivíduos, como é o caso das identidades. Para Davis (2006, p. 387), a visão tradicional do indivíduo é superada por elementos contemporâneos que são pautados nos aspectos sociais, individuais e pessoais; "a individualidade é endógena à interação social". O processo de formação das identidades envolve a maneira como o indivíduo enxerga a si mesmo e as imagens sociais.

That is, individuals form self-images not in terms of social categories
assignable to them by others but directly through their interaction with
others in social groups. Specifically, individuals choose to belong to or
participate in social groups with characteristics they believe fit their
own, thus choosing a social image that comes closest to or coheres best
with their own personal image of themselves. The coherence or inco-
herence - a kind of cognitive dissonance - between personal image and
social image, then, is what motivates individual actions and choices.
(Davis, 2006, p. 381).

As identidades são entendidas por Davis (2009a) como um conjunto de aspectos individuais e pessoais que formam a identidade social - essa dis12 Esta fase de transição é marcada pela crítica à visão neoclássica relacionada ao individualismo metodológico. 
tinção entre identidades pessoal, individual e social, que vai além de categorizações sociais, é uma das principais contribuições de Davis em relação a Akerlof e Kranton, March, Sen, Kirman e Teschl. Para Davis (2009a), as identidades envolvem aspectos como gênero, religião, etnia, grau de parentesco; mas também incluem descrições particulares dos próprios indivíduos ("autoimagem") e caracterizações baseadas na identificação com outras pessoas.

Davis (2006) diferencia o estudo das identidades sociais em três visões: i) de Akerlof e Kranton (2000), que possui elementos neoclássicos de maximização da utilidade para tratar de identidades; ii) de Sen, que transforma essa visão tradicional da Economia e introduz na análise do comportamento individual à questão dos grupos sociais; iii) de Kirman, que rompe completamente com as bases neoclássicas e que analisa o comportamento com base em redes sociais. Davis (2006) aponta esta última visão como mais complexa e apropriada para tratar dos processos de mudanças de identidades, o que poderia indicar que a contribuição de Davis é complementar à de Kirman. Entretanto, Davis apresenta diferenças e avanços ao definir e diferenciar três variedades de identidades: individual, pessoal e social, que não estão em Kirman.

Assim, uma das discussões que permeia o estudo das identidades é a forma como são abordadas. Diferente de Davis, os autores citados - Akerlof e Kranton, March, Sen, Kirman e Teschl - conceituam as identidades com base nos aspectos sociais e/ou pessoais, sem fazer diferenciação entre as identidades pessoais e individuais. Assim, por mais que Akerlof e Kranton, March, Sen, Kirman e Teschl não "ofusquem" a identidade social sob as identidades pessoal e individual, o fato de a identidade social ligar precisamente as outras duas variedades (pessoal e individual) é a principal contribuição de Davis, como será visto na seção seguinte.

\subsection{Identidades pessoal e individual}

Diferente dos outros autores já citados neste artigo, Davis (2009a), além de levar em conta elementos pessoais, faz a diferenciação entre a identidade pessoal, ligada à primeira pessoa do singular ("eu"), e a identidade 
individual, ligada à terceira pessoa do singular ("ele"). ${ }^{13}$ Enquanto que as identidades pessoais consideram aspectos particulares de cada ser humano, as identidades individuais são formadas no meio social (Davis, 2009a).

Individuals' personal identities, I claim, are constructed by individuals themselves, while their individual identities are socially constructed in terms of their different group memberships. Yet because people socially identify with others, individuals draw on their socially constructed individual identities in constructing their personal identities, thus making the former part of the latter. (Davis, 2009a, p. 79).

Diferentemente das identidades pessoais que envolvem apenas um ponto de vista com uma origem específica, as identidades individuais possuem discurso com distintas percepções da sociedade e em diferentes locais (Davis, 2009a). As identidades pessoais são representadas por Davis (2009a) por meio das características próprias do indivíduo, que é visto como sujeito único que inclui suas descrições pessoais e suas potencialidades de mudanças. Já as identidades individuais compõem diferentes percepções sobre um indivíduo, com base em categorias e interações sociais.

Davis (2009a) resume as diferenças entre identidades pessoais e individuais em quatro tópicos: i) essas identidades podem entrar em conflito quando se pretende identificá-las na realidade; ii) as identidades individuais possuem padrões mais estáveis do que as identidades pessoais, que são mais sensíveis às mudanças; iii) as identidades individuais tendem a incorporar as identidades pessoais, pois em certo ponto essas últimas estão inseridas nas primeiras; iv) por mais que seja maior a amplitude das identidades individuais, as identidades pessoais não são reduzidas a estas.

É preciso deixar claro que, para Davis (2011), a concepção tradicional de indivíduo na teoria econômica neoclássica não considera a individualidade em seu sentido amplo, apenas usa o termo "individual" para apontar a 13 Apesar de não utilizar os mesmos termos, Goffman (1988) também propõe uma diferenciação entre "identidade do eu", "identidade pessoal" e "identidade social". Conforme o autor, a primeira refere-se à subjetividade do indivíduo que forma sua identidade com base nas suas experiências de vida; a segunda indica que, apesar de a identidade possuir elementos particulares, estes são reconhecidos e compartilhados pelo meio social; e, a "identidade social" considera os atributos definidos no contexto social. Para Goffman, tanto a identidade pessoal quanto a social possuem, em graus diferentes, a influência do meio e da história do indivíduo. Goffman (1988) diferencia em alguns aspectos a "identidade pessoal" do que ele chama de "identidade do eu". A primeira refere-se aos aspectos surgidos socialmente, antes mesmo do indivíduo nascer (exemplo: linguagem); a "identidade do eu" é tratada como algo subjetivo, próprio do indivíduo, como o caso do seu nome. Davis (2009a) denomina de "identidade pessoal" as formações pessoais, Goffman (1988) utiliza o mesmo termo para delinear aspectos particulares que surgiram socialmente, o que Davis (2009a), por sua vez, chama de "identidade individual". 
autonomia do indivíduo em relação aos demais. ${ }^{14}$ "Economics, in fact, takes the individual as given, and operates on the implicit assumption that one particular conception of the individual, indeed one of well-established lineage - the subjectivist view - successfully explains individuality" (Davis, 2003, p. 1).

Davis (2003) refere-se ao fato de compreender o individualismo não do ponto de vista completamente isolado de qualquer aspecto histórico e social, mas de considerar o indivíduo como um ser particular, diferente dos demais, e que, ao mesmo tempo, comporta-se em um ambiente social e econômico. Por mais que exista a formação pessoal da identidade, não há como ignorar situações provocadas socialmente, isso justifica a presença de um "individualismo ontológico" diferente do "individualismo metodológico" neoclássico. De acordo com Davis (2009b), em algumas situações, autores consideram o individualismo metodológico como associado a uma "forma sólida" de individualismo ontológico. No entanto, essa associação, segundo o autor, considera apenas a existência dos indivíduos, enquanto que uma "forma geral" de individualismo ontológico entende que os indivíduos estão entre tantas outras coisas que existem no mundo (Davis, 2009b).

É por isso que a identidade individual de Davis (2009a) é vista como detentora de aspectos sociais. Alguns exemplos de sistemas vinculados a esse tipo de identidade são: os títulos de identificação dos eleitores (usados para evitar fraudes como o voto duplo), os registros de comprovação de desempenho educacional (utilizados para determinar a formação do indivíduo) e o sistema de identificação biométrica (com vários propósitos) (Davis, 2009a). Esses sistemas para identificação individual são criados e seguidos por grupos de pessoas, e não por um único indivíduo.

Para Davis (2009a, p. 81), a identidade individual representa:

[...] tool used to track and re-identify individuals across change for a whole variety of different reasons: legal responsibility determination, rights elaboration, market contract compliance, pension and social services delivery, medical treatment, education and training, birth and death verification, experimental investigation, and so on. Parallel to these multiple ways in which individual identity concept is constructed, moreover, there are also all the technologies used as tracking mechanisms for individuals: names, number assignments, biometric tech-

14 "A possibilidade de individualizar as pessoas é uma questão-chave para o estudo do comportamento humano. Através de 'como' o indivíduo age é possível descobrir a sua personalidade, ou seja, a sua identidade pessoal. A identidade pessoal atua como se fosse uma marca da personalidade individual que nos diz como o indivíduo atua no ambiente social e a descoberta dessa identidade possibilitaria a aprendizagem sobre o ambiente econômico" (Marin, 2006, p. 603). 
niques (photographs, fingerprints, DNA identification, dental records, etc.), surveillance, and incarceration or institutionalization. In this history, it is the individual identity concept clearly, not the personal identity concept that is foremost and central, in the construction of individuality.

Compreende-se a identidade individual como a atribuição de características aos indivíduos de modo a enquadrá-los em uma categoria social, tal como: criança, adolescente, graduado, mestre, doutor, aposentado, etc. "Individual identity concepts generated from social conflict and efforts to exercise power include such cases as: trade union member, immigrant, welfare recipient, insider trader, and terrorist" (Davis; Marin, 2007, p. 7).

As identidades individuais consideram a forma como a maioria da sociedade enxerga o indivíduo; a identidade pessoal considera reflexões sobre si mesmo. Outra diferença apontada por Davis (2009a) é que, como as identidades individuais possuem ligações com sistemas criados socialmente, elas são mais difíceis de serem modificadas quando comparadas às identidades pessoais. Mesmo que o emprego e a renda do indivíduo alterem-se com o passar do tempo, permanece a identificação individual desta pessoa de contribuinte e futuro beneficiário da aposentadoria (Davis; Marin, 2007).

Unlike their individual identities, which are determined socially by others, individuals' personal identities are determined individually (albeit under the influence of social conceptions of their individual identities). This implies that, as individuals' narratives about themselves change over their lifetimes, so also do their personal identities, or how they see their identities. In contrast, their individual identities are socially constructed by others so as to be essentially unchanging over their lifetimes, since the social processes which govern these third-person accounts aims to consistently track individuals through change. (Davis, 2009a, p. 83).

As identidades individuais são determinadas pela sociedade, que cria estereótipos que perduram por longos períodos de tempo. A identidade pessoal representa determinações individuais e, apesar de não ignorar completamente os fatores sociais - o indivíduo não é isolado -, permite o discurso próprio e a personalidade de cada ser humano, que não é imposta socialmente (Davis, 2009a).

Davis (2009a) esclarece que, por mais que as identidades pessoais não possam ser reduzidas às identidades individuais, as primeiras não consideram o indivíduo como isolado das identidades individuais.

Indeed, when individuals form personal identity narratives, their content often clearly reflect their social roles and identifications with others. 
While I argue below that individuals' personal identities cannot be reduced to their individual identities, this does not imply that the content of individuals' personal identities has origins independent of the content of their individual identities. Whether or not this is the case raises difficult philosophical issues that need not be sorted out for my purposes here. Rather, it is sufficient to state the obvious: society's conceptions of individual identity constrain or limit the degrees of freedom individuals can exercise in producing personal identities for themselves. (Davis, 2009a, p. 91).

Para Davis (2009a), ao considerar a abordagem das identidades, é importante levar em conta tanto a identidade pessoal quanto individual, e a forma de conciliar isso é via identidade social, conforme esquematizado na Figura 1.

\section{Figura 1 Identidades pessoal, individual e social}

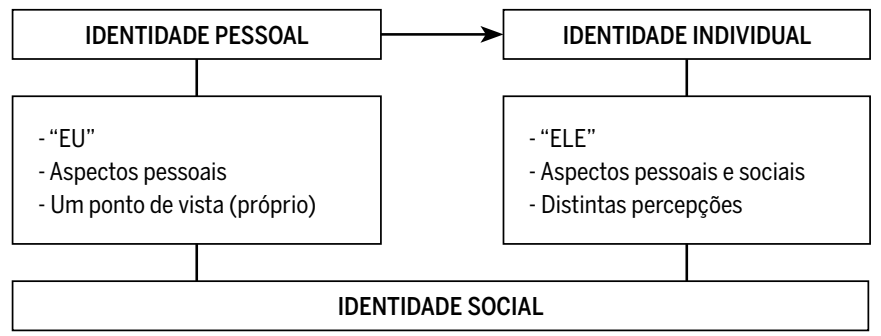

Fonte: Elaboração dos autores com base em Davis (2009a).

Davis (2009a) sugere, então, o estudo das identidades sociais, uma vez que estão baseadas no discurso da primeira pessoa do plural ("nós") representam um elo entre a identidade pessoal, com narração na primeira pessoa do singular ("eu"), e a identidade individual, baseada na terceira pessoa do singular ("ele"). Ou seja, a identidade social representa um elo entre o "eu" e o "ele" por meio do "nós", como será visto em seguida.

\subsection{Identidade social}

A identidade social é vista por Davis (2009a) como um conceito geral que liga a identidade pessoal e a identidade individual. É importante destacar que a visão particular de Akerlof e Kranton sobre as identidades sociais, de que os indivíduos identificam-se com outras pessoas via categorizações sociais, é diferente da ideia de identificação de um indivíduo com outro(s) 
por meio de instituições, estruturas, grupos e interações sociais (Davis, 2007). Este é mais um elemento, além da distinção entre identidades pessoal e individual, que demonstra uma importante diferença da contribuição de Davis sobre as identidades na Economia, em comparação a autores como Akerlof e Kranton e March.

Davis (2006) diferencia a "abordagem sociológica das identidades" e a "abordagem da identidade social". A primeira refere-se ao fato de os indivíduos possuírem papéis e posições dentro de estruturas sociais preestabelecidas que condicionam as identidades. Já a segunda aborda a relação entre categorias sociais e características individuais para tratar das identidades sociais também como algo próprio dos indivíduos, diferente de considerar os indivíduos como pertencentes unicamente ao meio social (Davis, 2006). É neste último sentido que Davis (2006) encontra uma aproximação da individualização aos aspectos sociais, isto é, das identidades pessoal e individual por meio da identidade social.

A maneira como a identidade social é abordada por Davis (2009a) não é referente a um quadro sociológico antiquado ("abordagem sociológica das identidades"), que condiciona as pessoas exclusivamente aos padrões estruturais e culturais, como entendido por Akerlof e Kranton (2005), March (1994), Sen (2015) e Kirman e Teschl (2006). A ideia de identidade social proposta por Davis (2009), diferente das demais, pertence a uma dimensão ontológica que considera os aspectos pessoais e individuais dentro de um contexto social ("abordagem da identidade social").

Para Davis (2006, p. 372-373), a identidade social representa a identificação das pessoas com outras ou, de outra forma, "[...] the idea that the individual takes on a group identity by ascribing herself characteristics belonging to a group. That a person's individual characteristics are group characteristics, however, invites one to ask how the individual is still an individual".

Davis e Marin (2007) apresentam a identidade social como correspondente à identificação dos indivíduos com outros do mesmo grupo (família, amigos, colegas do trabalho, etc.) ou de grupos sociais diferentes, mas que possuem alguma convergência (religião, etnia, língua, etc.). No entanto, essa identificação dos indivíduos com outras pessoas pode seguir diferentes direções que dependem de quem faz a identificação e das condições que são apresentadas.

Ao invés de considerar os extremos sociais ou individuais, Davis (2014) entende que as pessoas são individualizadas ao diferenciarem-se das de- 
mais por seus conjuntos específicos de identidades sociais. Não há como isolar os indivíduos de um contexto social. Para Davis (2014, p. 1), "individuals are first and foremost members of social groups, and their identification with those groups causes their behavior to reflect the interests of those social groups". Os indivíduos não são agentes desprendidos de um grupo, eles atuam como representantes deste. A identificação pode ocorrer com diversos grupos sociais, conforme a classe, o nível de escolaridade, o sexo, as ideologias, sendo que as pessoas podem ser descritas por diferentes composições de identidades (Davis, 2014).

Davis e Marin (2007) descrevem que o indivíduo é sempre social, de modo que as identidades pessoal e individual devem ser vistas em termos da identidade social. Segundo os autores, a identificação dos "indivíduos" com os outros pode acompanhar sentidos diferentes, variando conforme quem é o responsável pela identificação (quem está identificando e quem está sendo identificado). Assim, é possível elencar quatro variedades de identidades sociais: i) a identificação do indivíduo com outro (exemplo: identificar-se com um amigo); ii) a identificação do indivíduo com grupos de pessoas (exemplo: identificar-se com um grupo cultural de linguagem semelhante); iii) a identificação do indivíduo com outro por terceiros (exemplo: agentes sociais identificam o indivíduo com base na sua composição familiar); iv) a identificação do indivíduo, por terceiros, com grupos de pessoas (exemplo: estatísticos identificam o indivíduo em categorias de idade, gênero, cor, etc. $)^{15}$ (Davis; Marin, 2007, p. 6).

Nessa concepção de identidade social, Davis e Marin (2007) consideram que a identidade individual está presente quando citam a variedade "iv", ou seja, quando descreve-se, por terceiros, as características de um indivíduo como sendo representante de uma categoria ou um grupo social. Entretanto, segundo os mesmos autores, como os indivíduos não são meros objetos, no sentido de serem apenas "coisas definidas por terceiros", existe a identidade pessoal incorporada na definição de identidade social que está relacionada principalmente às outras três variedades de identidades sociais citadas anteriormente (i, ii, iii). Para os autores, isso não indica

15 Para Darity, Mason e Stewart (2006), os indivíduos, ao formarem identidades, utilizam informações de vários grupos, como a família, os amigos, os colegas de trabalho, a publicidade, etc. Além disso, essas informações podem ter pesos diferentes conforme as oportunidades que surgem e as mudanças sociais que ocorrem. Por mais que as identidades raciais possuam elementos biológicos, elas são construções sociais deliberadas, uma vez que as fronteiras raciais são também um sinal de diferenças nas oportunidades econômicas. 
que as identidades pessoal $\mathrm{e}$ individual não estejam relacionadas, uma vez que aquilo que os outros pensam sobre uma pessoa em relação aos outros indivíduos ou grupos também interfere no que a própria pessoa pensa sobre essas relações.

Thus, as it seems reasonable to say that an individual's personal identity somehow incorporates their own identification with other individuals and groups, as this is influenced by what third parties think about this identification, all four types of social identity enter into the individual's personal identity. (Davis; Marin, 2007, p. 8).

De acordo com Davis e Marin (2007), a variedade "iii" - a identificação do indivíduo com outro por terceiros - é uma questão relacional, da relação entre o indivíduo e a(s) relação(s) individual(ais). Já na variedade "iv" - a identificação do indivíduo, por terceiros, com grupos de pessoas - é uma questão de pertencimento a uma classe ou categoria, a pessoa é simplesmente um membro de um grupo, sem importar a sua relação com este.

O conceito de identidade pessoal, portanto, não inclui apenas o indivíduo como um sujeito, mas também como um agente - um ser ativamente envolvido nas relações complexas que envolvem a identidade social e sua formação individual (Davis; Marin, 2007). "Thus a fuller definition of personal identity is that it lies in individuals' active and reflexive negotiation of their complex social identities" (Davis; Marin, 2007, p. 10).

Conforme Davis e Marin, a identidade pessoal, apesar de estar definida com base na identidade social - como os indivíduos se relacionam com as outras pessoas -, não se reduz à ela. Isso ocorre pois a identidade pessoal, segundo os mesmos autores, traz a ideia de um indivíduo como "agente reflexivo". Da mesma forma, apesar de a identidade social ser construída com base na identidade individual, não se reduz a esta, pois abrange a determinação oriunda de terceiros (Davis; Marin, 2007).

De forma geral, Davis e Marin (2007, p. 14) utilizam o conceito de identidade social para justificar que os indivíduos "buscam identidades pessoais emolduradas por suas identidades sociais", mas que nenhuma variedade de identidade - social, individual e pessoal - pode ser eliminada.

Por mais que os indivíduos relacionem-se uns com os outros e sejam formados por aspectos sociais, é preciso compreender a sua capacidade de individualização (Davis, 2003). Considerar somente o social ou exclusivamente o individual é incorrer na antiga dicotomia "indivíduo versus social", que fecha os olhos para o contexto real de ligação entre esses dois elementos. Segundo Marin (2006, p. 605), "para Davis, a forma pela qual 
os indivíduos ocupam diferentes posições nos grupos sociais - a capacidade do indivíduo de se autoimpor coisas -, seria a base para distingui-los".

A identidade social apresenta-se como um link entre as identidades pessoal e individual e aproxima os fatores cognitivos, sociais e institucionais (Davis, 2009a). Davis (2006), ao propor essa conexão, considera que a identidade pessoal permite a existência de mudanças, e são justamente elas que podem ser impulsionadas por forças sociais. Não há como desconsiderar o contexto social ou os fatores pessoais; as alterações que ocorrem nos comportamentos dos indivíduos e nas identidades são oriundas de fatores internos combinados com externos, e vice-versa.

Para Davis (2009a), ao considerar a identidade social de maneira ampla, uma forma de entender a sua importância é com os "andaimes socioinstitucionais". Conforme Clark (1997 apud Davis, 2009a), a mente humana possui limitações de processamento de informações e as instituições sociais criam "andaimes"16 para a realização de atividades que não são facilmente executadas pelos indivíduos. Para Davis (2009a), os "andaimes socioinstitucionais" interferem nas atividades humanas e também são influenciados pelos próprios indivíduos e, por isso, não são completamente externos às pessoas. Esses "andaimes" gerados socialmente criam as identidades individuais e impulsionam as identidades pessoais (Davis, 2009a). Ou seja, os indivíduos possuem identidades pessoais e individuais constituídas por suas identidades sociais (Davis; Marin, 2007).

O interessante também desta concepção é que Davis (2009a) aproxima-se das contribuições de Veblen (1983), que entende as instituições como hábitos de pensamento de uma sociedade e que, portanto, poderiam ser consideradas como "andaimes socioinstitucionais" dos comportamentos. Essa ideia de Davis (2009), de que as instituições sociais não são completamente externas aos indivíduos, vai ao encontro das instituições de Veblen (1983), pois são formadas pelos hábitos e pelos instintos, ${ }^{17}$ com base em diferentes contextos históricos e sociais.

$\mathrm{Na}$ interpretação de Davis (2009a), os "andaimes" compõem as identidades sociais e aproximam as identidades individuais, constituindo-se

16 "[...] The social scaffolding idea relies on a strong contrast between structure and agency in that a scaffolding is a structure created by agents" (Davis, 2009a, p. 92).

17 Para discussão sobre instintos e hábitos no comportamento humano segundo Veblen, ver: The Instinct of Workmanship and the Irksomeness of Labor (1898) e The instinct of workmanship and the state of the industrial arts (1914). 
como base para descrever os quadros sociais que interferem na formação das identidades pessoais. Esta relação das identificações pessoais e individuais com as sociais decorre, para Davis (2009), da exteriorização das capacidades cognitivas por parte dos indivíduos com o intuito de aprimorá-las via processos sociais.

Davis (2009a) exemplifica isso por meio do registro de desempenho educacional (boletim): o indivíduo preocupa-se com o desenvolvimento pessoal baseado na sua identidade; os "andaimes socioinstitucionais" apresentam-se como resultados das construções sociais que são formados para organizar esse processo e delimitar o desenvolvimento pessoal. "That is, individuals' narratives about themselves are not just about how their personal experiences cohere, but are also about how their experiences in interaction with others are part of the narratives they produce about themselves" (Davis, 2009a, p. 83).

Davis (2014) resume a distinção entre a identidade social e pessoal da seguinte maneira: i) categorias: o lado social condiciona as pessoas aos elementos sociais, como é o caso dos processos estatísticos realizados por organizações que classificam os indivíduos em categorias específicas (cor, religião, idade, gênero, etc.); ii) relações: o caráter pessoal permite a atuação dos indivíduos e a sua relação com o grupo social, tornando-os menos dependentes de caracterizações preestabelecidas.

Essa forma de descrever a identidade social com base em "categorias" e "relações" é feita, conforme Davis (2014), por psicólogos sociais para justificar a presença de elementos sociológicos e autoconstrutivos. Para o autor, as "identidades sociais relacionais" indicam diversos papéis sociais que conectam-se; já as "identidades sociais categóricas" correspondem aos grupos de pessoas que possuem características em comum.

Para Davis (2014), os grupos de pessoas interferem na formação dos papéis sociais que estão inseridos nas "identidades relacionais". Estas, por sua vez, influenciam na maneira como são delimitadas as "identidades categóricas". A identidade é relacional, pois depende da posição que o indivíduo possui no relacionamento com o grupo; mas é também categórica, pois pode indicar o compartilhamento em categorias de características entre as pessoas (Davis, 2014).

Essa heterogeneidade de identidades e grupos sociais interage sobre diferentes aspectos e descreve o que é chamado de "interseccionalidade" (Davis, 2014). Exemplo disso é o caso de pessoas de distintas etnias que 
se identificam em uma mesma classe social ou religião. Para Davis (2014, p. 14), "intersectionality, again, is when individuals are members of multiple social groups and have multiple social identities".

Essa mistura de diferentes identidades dificulta a delimitação de indivíduos extremamente favoráveis ou completamente contra um grupo, uma vez que, em algum sentido, os interesses e as crenças relacionam-se. Para Davis (2014), essa situação cria um problema de estratificação na Economia que condiciona as pessoas apenas a certos grupos para explicar fatores como a desigualdade. ${ }^{18}$

As identidades sociais categóricas são formadas socialmente pela elaboração de procedimentos estatísticos que visam estratificar os indivíduos em categorias específicas por meio de agências governamentais, publicitárias ou outras organizações (Davis, 2014). No entanto, as pessoas possuem pouca influência sobre esse tipo de identidade, o que oferece certo poder de interferência apenas nos contextos relacionais.

Uma das maneiras de identificação é representada por grupos sociais e papéis criados socialmente, com alto ou baixo grau de consciência dos indivíduos (Davis; Marin, 2007). Para Davis e Marin, a identificação com outra pessoa tem bases psicológicas e pessoais, muitas vezes com menor grau de deliberação. No entanto, conforme os mesmos autores, a identificação dos indivíduos por terceiros, como categorizações feitas por órgãos governamentais, é formalmente pensada e possui o interesse de outrem.

O indivíduo possui uma identidade pessoal, mas não no seu sentido exclusivamente autônomo; leva em conta também a identidade social. Como identificado em Davis (2009a), para Granovetter (2000), é preciso construir uma teoria em que contextos, estruturas sociais e indivíduos sejam considerados de forma integrada. "The challenge for the new century is to build theory for the more general case, where contexts, structures and individual actions interact and change together. The world has not stood still, and theory has a lot of catching up to do" (Granovetter, 2000, p. 24).

Granovetter entende que o comportamento e as instituições devem ser compreendidos com base nas relações sociais, pois não há como dissociar esses elementos. Este fenômeno é chamado de embeddednes, de modo que 18 Davis (2014) analisa a estratificação e as identidades. A "interseccionalidade" sugere que esta forma de estratificar os indivíduos em grupos deve ser superada, pelo menos em parte, com a concepção de "identidades transversais" de grupos sociais. O autor pergunta-se como é possível dividir os indivíduos em grupos se estes podem pertencer a diversos grupos ao mesmo tempo com diferentes relações de poder, o que pode gerar conflitos sociais. 
"the argument that the behavior and institutions to be analyzed are so constrained by ongoing social relations that to construe them as independent is a grievous misunderstanding" (Granovetter, 1985, p. 481-2).

O indivíduo, em Davis (2009a), é vinculado às relações interpessoais, o que evita os extremos de ausência ou completa socialização dos indivíduos. As pessoas não estão isoladas de um ambiente social e institucional; não se comportam como "átomos" e nem agem exclusivamente reduzidas às construções sociais e culturais (Granovetter, 1985). Por mais fisiológica que algumas características apresentem-se, elas estão sujeitas, em algum grau, às mudanças históricas, sociais e institucionais.

Para Davis (2003), o comportamento é entendido dentro dos aspectos pessoais que envolvem as concepções e experiências próprias de cada ser, mas também com base na individualização das pessoas que interagem na sociedade. $O$ processo de individualização não leva em conta apenas elementos pessoais, mas a interação com o meio social, o que caracteriza o "indivíduo externalista" de Davis (2014), diferente do "indivíduo internalista" 19 da Economia Pura/Tradicional.

A identidade social de Davis (2009a) representa a possibilidade de considerar conjuntamente as dimensões cognitivas, sociais e institucionais do comportamento, apresentando-se como uma alternativa às visões reducionistas e que consideram o indivíduo como exclusivamente isolado ou unicamente socializado. Isso é demonstrado por Davis por meio da diferenciação entre identidades pessoal e individual que formam a identidade social, como pode ser observado na Figura 2.

\section{Figura 2 Identidade social}

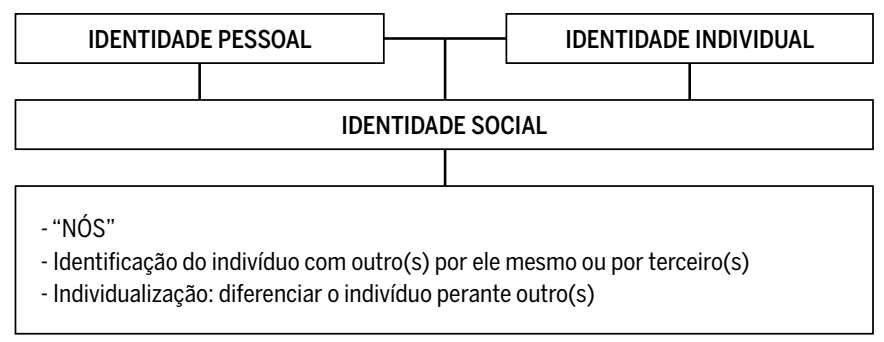

Fonte: Elaboração dos autores com base em Davis (2009a).

19 Para Davis (2010), essa concepção de "indivíduo internalista" admite a singularidade e o isolamento das pessoas, sem qualquer interferência social. 
Para Davis (2009a), os comportamentos e as identidades são resultantes de alguma deliberação; envolvem a capacidade de os indivíduos avaliarem as situações. Além de Davis (2009a) considerar a importância dos aspectos cognitivos, como a personalidade e a capacidade de deliberação dos seres humanos, ele também ressalta os fatores institucionais na abordagem das identidades quando se refere aos "andaimes socioinstitucionais". Pode-se relacionar esses "andaimes" com os hábitos e os instintos veblenianos, uma vez que para Davis (2009a) esses "andaimes" possuem elementos formados socialmente e que também são internos ao indivíduo. Os indivíduos possuem personalidades específicas (identidades pessoais), mas conectam-se com o contexto histórico e com a maneira como as outras pessoas pensam e agem, isto é, envolvem aspectos sociais e institucionais (identidades individuais).

A identidade social indica a existência de aspectos cognitivos, que envolvem a forma como o indivíduo pensa sobre si mesmo (autoconhecimento), a reflexão própria, a sua personalidade, a forma como o indivíduo enxerga o(s) outro(s) e a maneira como ele é reconhecido por outra(s) pessoa(s) - elementos das identidades pessoal e individual. Além disso, a identidade social possui aspectos sociais e institucionais representados pelos papéis sociais e pelos "andaimes socioinstitucionais", que incluem elementos formados socialmente e que, em algum grau, também são individualizados, como os hábitos e os instintos.

Com base nas ideias levantadas até aqui, é possível estruturar um quadro comparativo (Quadro 1) entre a abordagem de Davis e as visões de Akerlof e Kranton e dos outros autores referenciados neste artigo: March, Sen, Kirman e Teschl.

Conforme Davis (2006), uma das diferenças entre as abordagens sobre identidades acima citadas é que Akerlof e Kranton possui uma base neoclássica, Kirman e Teschl caracterizam-se pela abordagem da complexidade e Sen possui a abordagem do commitment. A abordagem das identidades de March, por sua vez, enquadra-se no âmbito sociológico.

Apesar de as abordagens acima admitirem contribuições da Filosofia, da Sociologia e da Psicologia para suas análises e de representarem importantes avanços na consideração do indivíduo na Economia, existem grandes diferenças entre as concepções. A abordagem de Akerlof e Kranton mantém, da Economia neoclássica, o individualismo metodológico, uma vez que a análise é reduzida à ação individual. Por outro lado, a abordagem de March aproxima-se do holismo metodológico, pois se volta aos aspectos 
sociais do comportamento humano, de modo a entender o indivíduo como um ser social. Enquanto que Akerlof e Kranton e March encontram-se na tradicional dicotomia "indivíduo versus social", Davis pode enquadrar-se no "individualismo ontológico" em seu sentido geral, em que "individuals are amongst the kinds of things that exist in the world" (Davis, 2009b, p. 261). Ou seja, por meio da identidade individual, Davis justifica o individualismo como detentor também de aspectos sociais.

Quadro 1 Comparação entre as abordagens sobre identidades na Economia recente

\begin{tabular}{l|l|l|l|l|l}
\hline & $\begin{array}{l}\text { Akerlof e } \\
\text { Kranton }\end{array}$ & March & Sen & $\begin{array}{l}\text { Kirman e } \\
\text { Teschl }\end{array}$ & Davis \\
\hline Abordagem & Neoclássica & Sociológica & Commitment & Complexidade & Ontológica \\
\hline $\begin{array}{l}\text { Presença } \\
\text { de modelos }\end{array}$ & $\begin{array}{l}\text { Modelos de } \\
\text { utilidade }\end{array}$ & $\begin{array}{l}\text { Mecanismos } \\
\text { Psicológicos }\end{array}$ & $\begin{array}{l}\text { Ausência } \\
\text { de modelos } \\
\text { formais }\end{array}$ & $\begin{array}{l}\text { Modelos } \\
\text { de escolha e } \\
\text { identificação }\end{array}$ & $\begin{array}{l}\text { Ausência } \\
\text { de modelos } \\
\text { formais }\end{array}$ \\
\hline $\begin{array}{l}\text { Tipos de } \\
\text { identidades }\end{array}$ & $\begin{array}{l}\text { Categorias } \\
\text { sociais }\end{array}$ & Papéis sociais & $\begin{array}{l}\text { Social e } \\
\text { pessoal }\end{array}$ & $\begin{array}{l}\text { Social e } \\
\text { pessoal }\end{array}$ & $\begin{array}{l}\text { Social, indivi- } \\
\text { dual e pessoal }\end{array}$ \\
\hline $\begin{array}{l}\text { Conceito de } \\
\text { autoimagem }\end{array}$ & $\begin{array}{l}\text { Relacionado } \\
\text { ao condiciona- } \\
\text {-mento social }\end{array}$ & $\begin{array}{l}\text { Relacionado } \\
\text { ao condiciona- } \\
\text {-mento social }\end{array}$ & $\begin{array}{l}\text { Relacionado } \\
\text { à identidade } \\
\text { pessoal, sem } \\
\text { condiciona- } \\
\text {-mento social }\end{array}$ & $\begin{array}{l}\text { Relacionado } \\
\text { à identidade } \\
\text { pessoal, com } \\
\text { elementos } \\
\text { sociais }\end{array}$ & $\begin{array}{l}\text { Relacionado } \\
\text { à identidade } \\
\text { pessoal e } \\
\text { individual }\end{array}$ \\
\hline $\begin{array}{l}\text { Conceito de } \\
\text { identidades }\end{array}$ & $\begin{array}{l}\text { "Com quem o } \\
\text { indivíduo se } \\
\text { identifica?" }\end{array}$ & $\begin{array}{l}\text { "Com quem o } \\
\text { indivíduo se } \\
\text { identifica?" }\end{array}$ & $\begin{array}{l}\text { "Quem é o } \\
\text { indivíduo?” }\end{array}$ & $\begin{array}{l}\text { "Com quem o } \\
\text { indivíduo se } \\
\text { identifica e } \\
\text { como ocorre } \\
\text { a mudança de } \\
\text { identidade?" }\end{array}$ & $\begin{array}{l}\text { "Quem é o } \\
\text { indivíduo?" }\end{array}$ \\
\hline
\end{tabular}

Fonte: Elaboração dos autores.

A abordagem de Akerlof e Kranton baseia-se no modelo de utilidade e a de March busca mecanismos psicológicos comuns entre as identidades/ papéis sociais e as regras, para entender o comportamento dos indivíduos. Da mesma forma, Kirman e Teschl sugerem a elaboração de modelos que compreendam a relação entre as escolhas e as diferentes maneiras como os indivíduos se identificam (múltiplas e dinâmicas identidades). Por outro lado, Davis dispensa modelos formais para tentar "enquadrar" os indivíduos e aproxima-se da concepção de Sen, pois considera as singularidades da espécie humana, o que dificulta modelagens formais adequadas. 
Nas abordagens de Akerlof e Kranton, March, Sen, Kirman e Teschl, o aspecto social caracteriza as identidades, mas não há uma definição correta do que seriam as "identidades sociais", no sentido de contemplar elementos pessoais, individuais e sociais. $\mathrm{Na}$ abordagem Akerlof e Kranton, as identidades sociais são vistas basicamente como ligadas às categorias socialmente criadas; em March, as identidades são confundidas com papéis sociais; em Kirman e Teschl, a identidade social é discutida em um contexto social e é diferenciada da identidade pessoal; em Sen, a identidade social é vista no sentido de pertencer a categorias ou grupos sociais e é diferenciada da identidade pessoal. Por outro lado, sem desmerecer a importância dos fatores sociais, Davis aprimora o conceito de identidades sociais e passa a incluir nele as identidades pessoal e individual, de modo a considerar não apenas os elementos formados socialmente, mas também as particularidades e os aspectos constitutivos de cada indivíduo.

Apesar de as abordagens citadas acima trazerem a ideia de "autoimagem" ligada às identidades, ou referenciarem alguns elementos pessoais, para Akerlof e Kranton e March essa autoimagem é condicionada apenas aos aspectos sociais, sem fazer aprofundamentos sobre os elementos pessoais. Kirman e Teschl (2006), por sua vez, consideram a existência de identidade pessoal em um sentido mais complexo, diferente de considerar apenas a autoimagem. Para Kirman e Teschl (2006), a identidade pessoal inclui processos cognitivos, motivações individuais e interesses próprios, ligados aos valores aceitos no ambiente social (identidade pessoal com elementos sociais). Sen (2015) também cita a existência das identidades pessoais, que incluem a identificação da própria pessoa sobre "quem ela era e como ela é atualmente", sem fazer ligação ou condicionar a identidade pessoal aos elementos sociais. Davis, aproximando-se mais de Sen, traz a autoimagem como característica da identidade pessoal, que inclui elementos pessoais de cada ser, como a personalidade. Em Davis, a autoimagem faz parte da identidade pessoal, que aproxima-se da identidade individual e constitui, juntamente com esta, a identidade social. A identidade pessoal, assim como a autoimagem, não é vista por Davis como condicionada unicamente aos fatores sociais, mas também como uma formação da personalidade do indivíduo e de suas escolhas. Apesar de a autoimagem ser construída na interação do indivíduo com outras pessoas, ela considera elementos pessoais, características próprias, que individualizam cada ser humano. 
As abordagens de Akerlof e Kranton e de March, por mais que utilizem o termo "identidades", não possuem um foco ontológico. Ambos permanecem no nível de análise do comportamento humano e suas influências, ou seja, questionam "com quem o indivíduo se identifica?". Kirman e Teschl (2006) também se preocupam com quem o indivíduo se identifica, mas diferenciam-se por compreender o comportamento em redes (modelos de escolha e identificação), buscando investigar o processo de mudança das identidades. Já a abordagem de Davis, que se aproxima de Sen, traz um foco ontológico para o estudo do indivíduo na Economia, pois problematiza "quem é esse indivíduo?". Assim, apesar de Sen e Davis terem uma abordagem ontológica para o estudo das identidades, o primeiro faz isso por meio das identidades pessoais, e o segundo utiliza a identidade social, em seu amplo significado, como forma de representar uma maneira de estudar o indivíduo em sua complexidade, considerando os aspectos pessoas, individuais e sociais.

\section{Considerações finais}

A abordagem de Davis, por meio da identidade social, permite um resgate do estudo do indivíduo na Ciência Econômica. Diferente de entender o indivíduo como isolado de qualquer interação social ou condicionado às formações da sociedade, a identidade social de Davis propõe que os indivíduos são agentes com suas características próprias e que existem elementos formados pela interação entre a cognição e a sociedade. $O$ discurso da identidade social baseado em "nós" considera tanto o "eu" - identidade pessoal - quanto o "ele" - identidade individual -, uma vez que esta abordagem compõe-se de uma autoimagem com características pessoais e fatores sociais e históricos.

Por mais pessoal que seja a identidade, e mesmo que não se reduza à identidade individual, não há como entendê-la de forma isolada, como algo "dado" unicamente por um estado biológico da espécie humana; é por isso que a identidade pessoal conecta-se com a individual. A própria constituição da identidade pessoal acaba, em certo sentido, inserindo-se no quadro individual, porque possui aspectos sociais. É por isso que as identidades sociais representam não apenas uma formação conjunta das identidades pessoal e individual, mas também dos aspectos cognitivos, so- 
ciais e institucionais, tais como: a personalidade, o autoconhecimento, o conhecimento por outro(s), as categorizações, os papéis sociais, os grupos sociais, os hábitos, os instintos e os "andaimes socioinstitucionais".

A teoria de Davis tem potencial para uma maior compreensão da diversidade de comportamentos em meio a relativas estabilidades sociais. Essa abordagem teórica, além de superar a maneira como os indivíduos são vistos na Economia Tradicional, também representa avanços em relação aos pensamentos de Akerlof e Kranton, de March, de Sen, de Kirman e Teschl. Os primeiros não referenciam os aspectos pessoais da identificação dos indivíduos e classificam as identidades sociais apenas como autoimagens individuais formadas por categorizações sociais. Na mesma linha, March concede importância primordial para os aspectos formados socialmente e considera identidade social como sinônimo de papel social; existe somente a liberdade de escolha de papéis, mas não a configuração de identidades. Kirman e Teschl apresentam as identidades em uma visão dinâmica, baseadas em comportamentos em rede, e, assim como Sen, apresentam as identidades nas categorias sociais e pessoais. Assim, por mais que Sen traga uma abordagem ontológica como Davis, ele deixa o conceito de identidades sociais muito vago.

Apesar de existir o caráter socialmente imposto e historicamente mantido dos papéis sociais, o comportamento e os indivíduos não se resumem a isso. Davis, diferente de outros autores - Akerlof e Kranton, March, Sen, Kirman e Teschl -, diferencia as identidades em sociais, individuais e pessoais e considera elementos além de categorias, tais como: a personalidade de cada indivíduo, as reflexões particulares, as imagens sociais e as instituições. Essas identidades conectam-se e são constituídas conforme o contexto histórico, a maneira como cada pessoa pensa individualmente e também em grupo. $O$ conceito de identidade social proposto por Davis leva em conta também os aspectos da individualização, que são detentores de algum grau de interação social, como é o caso dos papéis sociais.

Não é questionável a importância do contexto social na formação do comportamento humano, mas o problema está em considerar as identidades como comportamentos resultantes apenas do contexto social, sem fazer referência aos elementos pessoais e individuais. A abordagem de Akerlof e Kranton até cita a "autoimagem", mas inclusive esta é formada socialmente. March também cita a importância de elementos psicológicos, mas acaba mantendo seus estudos no âmbito das regras e dos pa- 
péis sociais. Além disso, tanto March quanto Akerlof e Kranton focam no estudo do comportamento, na tomada de decisão (ações) e sobre "com quem o indivíduo se identifica?" (categorias ou papéis) sem de fato refletir sobre "quem são os indivíduos?". Da mesma forma, Kirman e Teschl falam em identidades pessoais, incluindo processos cognitivos, motivações individuais e valores sociais, mas sugerem construções de modelos que contemplem as escolhas e as identificações dos indivíduos no plano das ações e comportamento. Sen, apesar de preocupar-se com quem é o indivíduo por meio das identidades pessoais, considera que as identidades sociais são formadas unicamente por elementos sociais, separadas das identidades pessoais.

Considerar que os indivíduos são complexos e de âmbito multidisciplinar não implica na relutância em discutir ontologia. Pelo contrário, é possível estudar os indivíduos por meio de fatores cognitivos, sociais e institucionais com base no conceito de identidades sociais de Davis. Esse autor apresenta-se como relevante para o estudo da Economia, pois, ao decompor as identidades pessoal e individual, é possível desenvolver um melhor protagonismo com padrões sociais - identidade individual e social.

Dessa forma, não é negável que Akerlof e Kranton e March contribuem para a Ciência Econômica no aprimoramento das análises neoclássicas, trazendo principalmente o elemento social como novidade para o estudo do comportamento. No entanto, os autores não trazem avanços na concepção ontológica, e utilizam-se da dicotomia "indivíduo versus social": Akerlof e Kranton mantêm o individualismo metodológico da economia neoclássica e March sustenta o holismo metodológico. Kirman e Teschl também trazem avanços, principalmente ao considerar o processo de mudança das identidades e o comportamento analisado em redes sociais. Sen, que mais se aproxima de Davis, também contribui nesta temática, pois traz uma abordagem sobre quem é o indivíduo. Entretanto, diferente desses autores, a identidade social de Davis retoma o estudo sobre a evolução dos indivíduos ("individualismo ontológico") e considera tanto aspectos pessoais, individuais quanto sociais. Assim, a perspectiva ontológica de Davis merece maior difusão, pois representa um enriquecimento no estudo dos indivíduos na Economia recente com base em um conceito amplo de identidades sociais. 


\section{Referências}

AKERLOF, G. A.; KRANTON, R. E. Economics and Identity. The Quarterly Journal of Economics, v. 115 , n. 3, p. 715-753, 2000.

AKERLOF, G. A.; KRANTON, R. E. Identity and the Economics of Organizations. Journal of Economic Perspectives, v. 19, n. 1, p. 9-32, 2005.

AKERLOF, G. A.; KRANTON, R. E. Identity, supervision, and work groups. American Economic Review: Papers \& Proceedings, v. 98, n. 2, p. 212-217, 2008.

AKERLOF, G. A.; KRANTON, R. E. Identity Economics: How Our Identities Shape Our Work, Wages, and Well-Being. Estados Unidos: Princeton University Press, 2010.

BÉNABOU, R.; TIROLE, J. Identity, morals, and taboos: beliefs as assets. The Quarterly Journal of Economics, v. 126, p. 805-855, 2011.

CHAFIM, F. V.; KRIVOCHEIN, C. Contribuições à crítica do individualismo metodológico na Economia. Revista Nexos Econômicos, v. 5, n. 9, p. 35-58, 2011.

DARITY JR., W. A.; MASON, P. L.; STEWART, J. B. The economics of identity: The origin and persistence of racial identity norms. Journal of Economic Behavior \& Organization, v. 60, p. 283-305, 2006.

DAVIS, J. B. The theory of the individual in economics: identity and value. London: Routledge, 2003.

DAVIS, J. B. Social identity strategies in recent economics. Journal of Economic Methodology, v. 13, n. 3, p. 371-390, 2006.

DAVIS, J. B. Akerlof and Kranton on identity in economics: inverting the analysis. Cambridge Journal of Economics, v. 31, n. 3, p. 349-362, 2007.

DAVIS, J. B. Identity and Individual Economic Agents: A Narrative Approach. Review of Social Economy, v. LXVII, n. 1, p. 71-94, 2009a.

DAVIS, J. B. Individualism. In: PEIL, J.; VAN STAVEREN, I. (eds.). Handbook of Economics and Ethics. Cheltenham, UK: Edward Elgar Publishing, 2009 b.

DAVIS, J. B. Neuroeconomics: Constructing identity. Journal of Economic Behavior \& Organization, v. 76, p. 574-583, 2010.

DAVIS, J. B. Individuals and Identity in Economics. New York: Cambridge University Press, 2011.

DAVIS, J. B. Stratification economics and identity economics. Cambridge Journal of Economics, p.1-15, 2014.

DAVIS, J. B.; DOLFSMA, W. Social Economics: An Introduction and a View of the Field. The Elgar Companion to Social Economics. Cheltenham: Edward Elgar Publishing, 2008.

DAVIS, J. B.; MARIN, S. R. Identity and Democracy: Linking Individual and Social Reasoning. Social Science Electronic Publishing, 2007. Disponível em: <http://ssrn.com/ abstract=1004077>. Acesso em: 7 dez. 2014.

FINE, B. The economics of identity and the identity of economics? Cambridge Journal of Economics, v. 33, n. 2, p. 175-191, 2009.

GODE, D. K.; SUNDER, S. Allocative Efficiency of Markets with Zero-Intelligence Traders: 
Market as a Partial Substitute for Individual Rationality. Journal of Political Economy, v. 101, n. 1, p. 119-137, 1993.

GOFFMAN, E. Estigma - notas sobre a manipulação da identidade deteriorada. Rio de Janeiro: LTC, 1988.

GRANOVETTER, M. Action and Social Structure: The Problem of Embeddedness. American Journal of Sociology, v. 91, n. 3, p. 481-510, 1985.

GRANOVETTER, M. A Theoretical Agenda for Economic Sociology. Stanford University, 2000.

HODGSON, G. M. The Evolution of Institutions: An Agenda for Future Theoretical Research. Constitutional Political Economy, v. 13, p. 111-127, 2002.

HODGSON, G. H. Meanings of methodological individualism. Journal of Economic Methodology, Petersburg, v. 14, n. 2, p. 211-226, 2007.

HODGSON, G. H. From pleasure machines to moral communities: an evolutionary economics without homo economicus. Chicago: The University of Chicago Press, 2013.

HORST, U.; KIRMAN, A.; TESCHL, M. Changing Identity: The Emergence of Social Groups. Economics Working Papers, Princeton: Institute for Advanced Study, School of Social Science, p. 1-30, 2007.

KERSTENETZKY, C. L. Individualismo Interativo - Um Ensaio Sobre o Individualismo Metodológico de Hayek. Estudos Econômicos, São Paulo, v. 37, n. 1, p. 101-128, 2007.

KIRMAN, A.; TESCHL, M. Searching for identity in the capability space. Journal of Economic Methodology, v. 13, n. 3, p. 299-325, 2006.

MARCH, J. G. A primer on decision making: how decisions happen. New York: The Free Press, 1994.

MARCH, J. G.; OLSEN, J. P. The logic of appropriateness. In: MORAN, M.; REIN, M.; GOODIN, R. E. (eds). The Oxford Handbook of Public Policy. Oxford: Oxford University Press, 2008.

MARIN, S. R. The theory of the individual in economics: identity and value. Economia e Sociedade [resenha], Campinas, v. 15, n. 3, p. 603-606, 2006.

MIROWSKI, P. Markets come to bits: Evolution, computation and markomata in economic science. Journal of Economic Behavior \& Organization, v. 63, p. 209-242, 2007.

ROSS, D. Individuals and identity in economics [Book Reviews]. Journal of Economic Methodology, v. 19, n. 4, p. 446-451, 2012.

RUTHERFORD, M. Institutions in economics: The old and the new institutionalism. Cambridge: Cambridge University Press, 1994.

SEN, A. K. Rationality and freedom. First Harvard University Press paperback edition, 2004.

SEN, A. Identity and Violence: The Illusion of Destiny. London: Penguin Books, 2007.

SEN, A. The fog of identity. Politics, Philosophy \& Economics, v. 8, n. 3, p. 285-288, 2015.

SHAFRITZ, J.; OTT, J. S.; JANG, Y. S. Classics of Organization Theory. Wadsworth Publishing, 2015.

THE ECONOMIST. Guru: James March. Online extra. 2009. Disponível em: <http://www. economist.com/node/14099644>. Acesso em: 22 fev. 2016. 
VEBLEN, T. Why is Economics not an Evolutionary Science? The Quarterly Journal of Economics, v. 12 , n. 4, p. 373-397, 1898.

VEBLEN, T. The instinct of workmanship and the state of the industrial arts. New York: The Macmillan Company, 1914.

VEBLEN, T. A teoria da classe ociosa: um estudo econômico das instituições. São Paulo: Abril Cultural, 1983.

\section{Sobre os autores}

AlineZulian - alinezulian@hotmail.com

Universidade Federal do Rio Grande do Sul (UFRGS), Porto Alegre, RS.

Solange Regina Marin -solange.marin@ufsc.br

Universidade Federal de Santa Catarina (UFSC), Florianópolis, SC.

Orlando Martinelli Júnior - orlando.martinelli@gmail.com

Universidade Federal de Santa Maria (UFSM), Santa Maria, RS.

\section{Sobre 0 artigo}

Recebido em 05 de setembro de 2015. Aprovado em 22 de novembro de 2016. 